\title{
The Effect of Perspective-Taking on Trust and Understanding in Online and Face-to-Face Mediations
}

\author{
Debby Damen ${ }^{1}$ (D) $\cdot$ Per van der Wijst ${ }^{1} \cdot$ Marije van Amelsvoort ${ }^{1} \cdot$ Emiel Krahmer $^{1}$
}

Published online: 2 September 2020

(c) The Author(s) 2020

\begin{abstract}
This research investigates the perspective taking process in online and face-toface mediations. In particular, it addresses the question whether a perspective taking technique-being asked circular questions-helps the establishment of mutual understanding and interpersonal trust between negotiators in online and face-to-face mediation settings. This question was studied in an experimental setting in which disputants had to solve a conflict face-to-face or online by the help of a professional mediator. During the interventions, the mediator either posed mainly circular (perspective-taking) or linear questions. It was expected that mediations in which circular questions were used would lead to a higher level of mutual understanding and interpersonal trust between the disputants, and - as a result— to a more satisfying, integrative agreement. Furthermore, this study examined whether the communication mode of the intervention (online, face-to-face) affected the re-establishment of disputants' interpersonal trust and understanding. The results of the study show that disputants' feelings of trust in and understanding of their interaction partner improved more in the face-to-face mediations than in the online mediations. These improved feelings of understanding and trust also predicted how satisfying and integrative disputants perceived the agreement to be. Moreover, disputants perceived their mediator to be more trustworthy and more professional in the face-to-face than in the online interventions. No effect was found for mediators' questioning style on disputants' improved interpersonal trust and mutual understanding. We discuss the effects of the questioning style of a mediator and conclude with reflections on reasons why these effects did not lead to differences in mutual understanding and interpersonal trust between the disputants.
\end{abstract}

Keywords Perspective-taking · Interpersonal trust · Mutual understanding · Online · Face-to-face $\cdot$ Mediation

Debby Damen

d.j.damen@uvt.nl

1 Tilburg Center for Cognition and Communication (TiCC), Department of Communication and Cognition, Tilburg School of Humanities and Digital Sciences, Tilburg University, PO Box 90153, 5000 LE Tilburg, The Netherlands 


\section{Introduction}

When disputants first enter a mediation session, the experienced lack of trust in each other and a poor understanding of each other's perceptions and feelings might make them feel unable to reach a solution for their conflict. Locked in their own perception of the situation, disputants often find themselves unable to reflect on how their behavior contributed to the conflict and are, therefore, often unwilling to view the problem from their counterpart's perspective (e.g., Deutsch 2006). This makes it challenging for disputants to negotiate a solution that is mutually beneficial and satisfying. As a neutral third party, the mediator's task is to assist disputants to take that other perspective, guiding them to resolve their interpersonal conflict and to re-establish the foundations that are necessary for a healthy, trustworthy future relationship.

Mediators have several possibilities to invite disputants to communicate openly, so that they come to better understand and trust each other during (and after) the negotiation. For instance, mediators can invite each disputant to explain the circumstances from their own perspective (e.g., "How did you feel at that time?"), or they can diverge from this self-oriented, linear (e.g., Cecchin 1987; Ryan and Carr 2001) path of questioning by inviting disputants to talk about their perception of the other's thoughts and feelings. The latter constitutes a circular interviewing style (e.g., Cecchin 1987; Selvini-Palazzoli et al. 1980; Tomm Tomm 1985, 1987a, b, 1988) that presupposes circular reasoning (Ryan and Carr 2001). Using circular reasoning, mediators emphasize that disputants' actions, thoughts and feelings are all interconnected. Hence, in a circular interview, mediators aim to discern differences in disputants' perceptions by posing questions that are mainly other-oriented. These interpersonal perception questions (Tomm 1985), such as "What do you think the other party needs in order to accept your offer?", oblige disputants to take the perspective of their counterpart while this person is present to hear their answer. In this way, misconceptions can be exposed and addressed. The literature, therefore, assumes that these other-oriented circular questions are able to transform (Putnam 2004) the negation process in such a way that disputants come to better understand each other, thereby allowing their relationship to be reshaped in a more positive light.

Posing circular questions as an interviewing style has been elaborately discussed in the field of family therapy (e.g., Adams 1997; Brown 1997, 2010; Cecchin 1987; Diorinou and Tseliou 2014; Fleuridas et al. 1986; Penn 1982; Real 1990; Selvini-Palazzoli et al. 1980; Scheel and Conoley 1998; Tomm 1984a, b, 1985, 1987a, b, 1988) and mediation practices (e.g., Brandon 2011; Brenninkmeijer et al. 2009; Choy 2005). In this literature, the effectiveness of the circular question is described on the basis of short conversation analyses. Although it is assumed that a circular interviewing style can establish feelings of mutual understanding and empathy between negotiating parties (e.g., Wilkinson 1992), this relationship has not been scientifically examined (e.g., Putnam 2004). To our knowledge, it has yet to be experimentally investigated whether circular questions that explicitly ask disputants to take the perspective of their counterpart have a 
stronger influence on the establishment of disputants' feelings of trust and understanding than more linear types of questions. In addition, if circular questions indeed contribute to feelings of mutual understanding and interpersonal trust, it remains to be explored whether these effects are preserved in settings in which parties are not physically co-present to negotiate. That is, face-to-face settings allow for greater physical proximity and interpersonal rapport due to the greater exchange of social, personal and non-verbal information (e.g., Cole and Blankley 2006; Goodman 2003). Following this line of reasoning, research argues that richer media (e.g., offline, face-to-face mediations) allow interlocutors to attain a higher level of interpersonal trust (Yuan 2003) and interpersonal understanding (e.g., Clark and Brennan 1993; Crook and Booth 1997; Thomson et al. 2001; Veinott et al. 1999) than leaner media (e.g., online mediations). Furthermore, the loss of non-verbal cues might disable mediators to come across as professional, understanding, and trustworthy (Beal 2000; Shah 2004). These assumptions, however, have not been tested experimentally in settings in which face-to-face and online mediations are directly compared. This study tries to fill this knowledge gap by examining the impact of circular questions in face-to-face and online mediations on the establishment of trust and understanding between disputants.

We have structured the rest of the paper as follows. In the next chapter, we first discuss the importance of establishing trust and understanding for negotiation success, followed by how disputants' perspective-taking might trigger feelings of trust and understanding. In this study, we define perspective-taking as disputants' reasoning about each other's mental states, triggered by the circular questions that are posed by the mediator during the intervention. Circular questions are defined here as a questioning style that invites disputants to take over their counterpart's viewpoint. We investigate the extent to which this questioning style improves disputants' feelings of understanding and trust, and whether these feelings influence disputants' conflict resolution. We conclude this section by discussing how the online intervention environment - in which non-verbal cues are absent-might hamper the mediator's ability to establish trust and understanding between the quarreling parties. After this section, we describe the research methodology of our online and face-toface mediations, followed by our analyses and results. We conclude by a discussion of our findings and directions for future research.

\section{Theoretical Background}

\subsection{Trust and Understanding in Mediations}

In a negotiation, disputants try to solve their dispute by negotiating an agreement that is beneficial for all parties involved. When a neutral third party-the mediator-assists disputants during this negotiation, this dispute resolution is termed as a mediation. Mediations aim at expanding disputants' interests in such a way that a basis for agreement arises (Carnevale and Arad 1996; Herrman 2009; Pruitt and Carnevale 1993). When disputants first arrive at the mediation, they are mostly focused on venting their reproaches and on blaming the other party for the conflict. 
As transformative coaches (Cole and Blankley 2006), mediators then have the important task to bend these reproaches into the underlying interests and to explore how much these interests collide. By focusing on communal values, beliefs and interests, and trying to unite what seem to be incompatible interests, the process is shaped in a more positive light and disputants might come to realize that they are both responsible for solving the conflict. When parties realize that they are dealing with a mixed-motive situation in a sense that the attainment of their own goals not only relies on their ability to be competitive but also on their ability to be cooperative (Thompson and Nadler 2002; Walton and McKersie 1965), the chances increase that the conflict will be solved satisfactorily via the mediation processes.

Literature shows that disputants' feelings of interpersonal trust and understanding affect the negotiation process (e.g., Butler 1999; Carnevale and Arad 1996; Moore 1994; Ross 2010). Both feelings of trust and understanding constitute important factors determining whether disputants are (perceived) to be cooperative bargainers and, as consequence, are able to negotiate a solution that is integrative and satisfying for all involved parties. More specifically, when negotiators trust each other and understand each other's interests, they trust that the other is also cooperatively motivated to negotiate truthfully and to attain a mutual beneficial outcome (e.g., Falk and Johnson 1977; Johnson 1971; 1975; Kimmel et al. 1980; Mayer et al. 1995; McAllister 1995; Naquin and Paulson 2003; Ross and LaCroix 1996). Interpersonal trust has been defined as a person's willingness to be vulnerable and to be dependent on the actions of another person (Rousseau et al. 1998; for a review see Ross and LaCroix 1996). It is a prerequisite to cooperative behavior (Deutsch 1958; Galinsky and Mussweiler 2001; Gambetta 1988; Kee 1970; Kimmel et al. 1980; Lindskold et al. 1986; Parks and Hulbert 1995; Ross and LaCroix 1996) and essential in reducing (interpersonal) conflict (Meyerson et al. 1996). Mutual understanding presupposes that disputants have a certain common-ground that consists of their mutual knowledge and beliefs, and their shared information about the situation (Clark and Carlson 1982). As trust, feelings of mutual understanding can be established by disclosing personal information, thereby enhancing feelings of mutual alignment and a feeling of a social identity (Thompson and Nadler 2002). Although someone's gain does not automatically mean that the other party has to sacrifice resources, negotiators often believe that their interests collide (Lax and Sebenius 1986). Mutual interests are often not discussed and this has a detrimental effect on reaching an optimal agreement (Thompson and Hrebec 1996). In order to reach a negotiated outcome that is also mutually satisfying for all parties involved, it therefore seems vital that disputants come to trust and understand one another.

One way to establish feelings of trust and understanding is to ask negotiators to read the mind of their counterpart (e.g., Evans and Krueger 2011; Fett et al. 2014). This perspective-taking implies that interaction partners try to get a clear understanding of how their partner's feelings are affected by the situation or circumstances. An ample body of research has evidenced the social and cognitive benefits of communicators' mental state reasoning. That is, perspective-taking can help people to feel more aligned (e.g., Davis 1996; Davis et al. 1996; Goldstein et al. 2014; Maner et al. 2002), thereby stimulating cooperation (e.g., Batson et al. 2002), helping and prosocial behavior (e.g., Chandler 1973; Clore and Jeffery 1972; Galinsky 
and Moskowitz 2000; Giammarco and Vernon 2014; Husnu and Crisp 2015; Mallet et al. 2008; Maner et al. 2002), and the establishment and sustainment of interpersonal (e.g., Galinsky et al. 2005; Shih et al. 2009; Todd and Galinsky 2014) and intergroup relationships (Boca et al. 2018). In addition, research has argued that instructing interlocutors to understand the other person's point of view positively influences negotiation processes. For instance, Neale and Bazerman (1983) showed that negotiators with high perspective-taking skills were able to negotiate agreements that were more valuable, partly because they stimulated the other party's concession rate. Furthermore, not only does perspective-taking lead to more feelings of trust and attraction between group members (Falk and Johnson 1977), negotiators engaging in perspective-taking are also better at cooperating and exchanging information (Johnson 1975; Falk and Johnson 1977), and are able to come up with agreements that are more creative (Falk and Johnson 1977) and efficient (Galinsky et al. 2008a, b; Galinsky and Mussweiler 2001; Johnson 1971), than negotiators who do not take the perspective of their interlocutor.

Perspective-taking can also be beneficial for the resolution of interpersonal conflicts, when disputants try to imagine the situation from their counterpart's view (e.g., Boca et al. 2018; Sessa 1996; see also Galinsky et al. 2011). In a study investigating the influence of perspective-taking on reducing intergroup hostility, Boca et al. (2018) invited participants to partake in a scenario study in which they represented one of the conflicting parties. Participants read a hostile reaction from their counterpart and responded to this harsh letter, subsequently reporting the amount of hostility they felt between them and the other party. In half of the situations, a mediator was present to assist participants in resolving the conflict. Boca et al. (2018) showed that the mediator's presence reduced the amount of hostility participants experienced. More importantly, the researchers showed that the success of the mediation was amplified when participants had been instructed to "put themselves in their counterparts' shoes" (p. 413), before they reported their feelings of mutually felt hostility.

To our knowledge, the findings by Boca et al. (2018) are the first to illustrate the important role perspective-taking might play in resolving interpersonal conflicts that are assisted by a mediator. However, the extent to which perspective-taking might influence a conflict's resolution is still unclear. Boca et al. (2018) focused on participants' feelings of hostility and did not examine whether participants actually understood their counterpart's perspective better or felt more understood by their counterpart due to these perspective-taking instructions. It thus remains to be investigated whether these feelings of mutual understanding were the underlying reason perspective-taking contributed to the conflict's resolution. Furthermore, in Boca et al. (2018), the perspective-taking instructions were not provided by the mediator. Boca et al. (2018) only examined the influence of the mediator's presence on conflict resolution and did not investigated the role the mediator might play in helping disputants to re-establish their feelings of mutual understanding. Particularly in reallife interventions, mediators aim at expanding disputants' mutual understanding by employing various discourse and questioning techniques inviting disputants to communicate and to engage in perspective-taking behavior. To our knowledge, however, 
the effect of these questioning techniques on disputants' improved feelings of mutual understanding has not been systematically examined.

\subsection{Circular Questions in Mediations}

One communication technique that has been argued to be very effective in establishing disputants' understanding of each other's viewpoints is exposing disputants to circular questions (e.g., Brown 1997, 2010; Fleuridas et al. 1986; Selvini-Palazzoli et al. 1980; Tomm 1987a, b, 1988) such as the interpersonal perception questions (Tomm 1985). By asking a quarreling neighbor John a question like: "John, how do you think your neighbor Mary will react to your accusations?", John is obliged to think about the effect his behavior has on Mary and about their relationship as neighbors. Hence, in each circular question lies an implicit request for trying to understand the other person and to understand how one's behavior provokes a response that affects the interpersonal relationship. On the other hand, a linear question such as "John, how do you feel about the broken glass?" looks at an event in isolation, enabling John to vent his own thoughts and feelings and validating his own perceptions and beliefs (i.e., "Mary wronged me by breaking the glass") without forcing him to consider Mary's perspective of the event.

Circular questions address reciprocity, and they invite disputants to take each their responsibility for the conflict (Kalff and Uitslag 2007). Since both disputants are responsible for the conflict, they are also both responsible to find its solution. For example, a circular question like "John, what do you think that Mary needs from you in order to fulfill your wish of keeping the shared front yard clean?", forces John to think about ways to contribute to the dispute's solution that also suit Mary's interests. Contrarily, a general, linear question like "John, what do you need from Mary?" focuses only on what John needs from the other party and not on what the other party needs from him. By also asking the reciprocity question to the other party (Mary), both disputants can reflect on the fact whether their counterpart has the right perspective on their personal needs, feelings and wishes. The power of a circular question in a mediation lies in the fact that perspective-taking takes place right in the presence of the other party. Disputants see and hear the other party taking over their perspective and they judge their counterpart's level of correctness. These communication techniquesif effective-might help develop the interpersonal rapport between disputants (Thompson and Nadler 2002), which consists of mutual attention, friendliness, spontaneous communication and physical closeness. The development of interpersonal rapport between disputants reduces tensions and facilitates the construction of mutual understanding - the feeling of being understood and understanding the other party - and interpersonal trust - the feeling of being trusted and trusting the other. Both mutual understanding and interpersonal trust are important factors influencing disputants' acceptance of and satisfaction with the negotiated agreement (Yuan et al. 2003). In addition, these factors also influence how mutual beneficial the agreement is perceived to be (Thompson and Nadler 2002). Although it is assumed that the circular interview has a powerful influence on establishing 


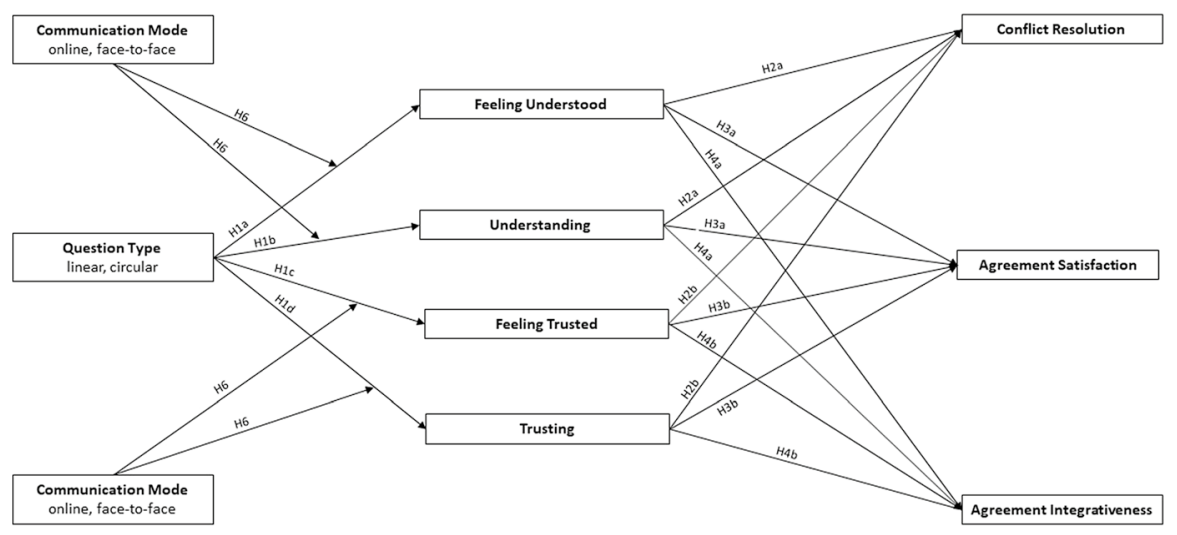

Fig. 1 Conceptual model of question type predicting conflict resolution, agreement satisfaction and agreement integrativeness via disputants' mutual understanding (feeling understood, understanding) and interpersonal trust (feeling trusted, trusting)

understanding and trust between disputants, empirical tests of the assumed relation in a mediation setting are yet to be performed. In particular, the relation between the perspective-taking communication technique-asking circular questions -and feelings of trust and understanding is investigated in this study. We present a conceptual model (Fig. 1) in which we test the following hypotheses:

H1 The use of circular questions by a mediator will increase the level of disputants' mutual understanding and interpersonal trust, in comparison to the use of linear questions. In particular, we expect that, after a mediation in which circular instead of linear questions were asked, disputants will:

a. ...feel that they are better understood by the other party

b. ...understand the other party better

c. ...feel more trusted by the other party

d. ...trust the other party more

H2 Disputants' improved feelings of (a) mutual understanding and (b) interpersonal trust will increase the likelihood of disputants finding a solution for their conflict.

Since perspective-taking has been found to lead to cooperative problem-solving and effective conflict resolution (e.g., Falk and Johnson 1977; Galinsky et al. 2008a, b; Galinsky and Mussweiler 2001; Johnson 1971, 1975), we expect that perspectivetaking (achieved by circular questions) will increase the chances of disputants finding a solution to their interpersonal conflict that is both satisfying and integrative (Fig. 1).

H3 Disputants' improved feelings of mutual understanding (a) and interpersonal trust (b) will lead to a greater satisfaction with the negotiated results. 
H4 Disputants' improved feelings of mutual understanding (a) and interpersonal trust (b) will lead to a negotiated agreement that is perceived to be more integrative.

In addition to these hypotheses, we explore the extent to which a circular interviewing style allows the mediator to create an environment in which he is trusted by parties (e.g., Schweitzer et al. 1997; see also "neutrality" in Cecchin 1987; Fleuridas et al. 1986; Scheel and Conoley 1998; Selvini-Palazzoli et al. 1980; Tomm 1987a, b; Wilkinson 1992; and "therapeutic alliance" in Ryan and Carr 2001). We hypothesize the following (Fig. 1):

H5 Mediators who use circular questions will be perceived to be more trustworthy, professional and impartial than mediators using linear questions during the intervention.

\subsection{Online Versus Face-to-Face Mediations}

The advancement of information technology has allowed negotiations to overcome the barriers in time and space. By means of digital media, bargainers are now able to negotiate with others who are not in their immediate presence. These $e$-negotiations or e-mediations (e.g., Bichler et al. 2003; Dannenman and Schoop 2011; Druckman et al. 2002, 2004, 2014; Schoop et al. 2003; Ströbel and Weinhardt 2003; see also Schoop et al. 2014) often use decision-(DSS) and/or negotiation support systems (NSS) ${ }^{1}$ that assist negotiators through the various stages of the online negotiation or mediation process. Studies examining the effectiveness of these online interventions often show that e-negotiations and e-mediations outperform interventions that take place without the support of electronic media (i.e., offline). For instance, in comparison to offline negotiations, e-negotiations have been argued to improve the negotiation's efficiency and effectiveness (e.g., Bichler et al. 2003), and to reduce time and social pressure, thereby stimulating bargainers' negotiation and communication skills (e.g., Köszegi and Kersten 2003). Furthermore, Druckman et al. (2004) argued that e-mediations might be more effective in terms of agreements reached and outcome satisfaction than offline mediations. That is, the authors showed bargainers reached more agreements and were more willing to compromise when they were assisted by an e-mediator than by a live (offline) mediator. ${ }^{2}$ This was especially the case when both bargainers jointly used the negotiation support system during the negotiation. On the basis of these findings, the authors concluded that online mediations in which bargainers were assisted by negotiation support system might prove to be more beneficial than offline mediations.

An interesting finding of Druckman et al.'s study (2004) was, however, that bargainers still preferred the offline intervention compared to the e-mediation. When a "live" mediator assisted the negotiators, negotiators experienced the negotiation more positively, viewing the offline mediator as being more helpful than the e-mediator.

\footnotetext{
1 See, for instance, the Negotiator Assistant (NA) (Druckman et al. 2002, 2004), VieNA (Druckman et al. 2014), and Negoisst (Schoop et al. 2003, 2014).

2 Findings by Druckman et al. (2014) indicated that-even though e-mediations stimulated bargainers' willingness to compromise- the final agreements were not more integrative than the agreements made with an offline mediator.
} 
Druckman and colleagues (2004) questioned whether the negotiators viewed the live mediation more positively than the online mediation because the offline mediator was perceived to be more human-like (e.g., Lee and Nass 2006), causing negotiators to attribute greater competence and trustworthiness to the offline mediator than to the e-mediator. Important to note here is that-during the offline interventions in Druckman et al. (2004) — negotiators were not in each other's presence during the negotiation. In fact, negotiators still negotiated separately and the mediator gave the instructions on hard copy to each negotiator separately. Druckman et al. (2004) compared this offline intervention to an e-intervention in which the mediator's instructions were provided to negotiators via a NSS. This means that in Druckman et al.'s (2004) offline and online interventions, negotiators did not negotiate synchronously, nor was the mediator co-present to assist negotiators, synchronously, during the intervention. Therefore, the communicative style of the mediator on disputants' rapport building could not be examined. In addition, it remains to be investigated to what extent Druckman et al.'s (2004) findings generalize to settings that compare synchronous offline and e-mediations.

There is some evidence to suggest that the online synchronous text-based negotiations might negatively affect the negotiation process and negotiators' rapport building. By comparing synchronous online (chat) negotiations and offline (faceto-face) negotiations, Van der Toorn, Van der Wijst and Damen (2015) examined the influence of the online medium on the negotiation's effectiveness and bargainers' rapport building. Van der Toorn et al. (2015) showed that negotiators performed equally well in both online and offline negotiations with regard to reaching an integrative agreement. However, Van der Toorn et al. (2015) also showed that the online medium negatively affected the negotiators' relationship. That is, negotiators' feelings of understanding and trusting each other were lower in the online text-based than in the face-to-face negotiations, especially with regard to negotiators' feeling of being understood and being trusted by their counterpart. These findings are in line with the Naquin and Paulson (2003), and Köszegi and Kersten (2003; see also Gattiker et al. 2007), who showed that bargaining online can have negative social-psychological consequences. By comparing face-to-face to online negotiations, Naquin and Paulson (2003) found that negotiators' interpersonal trust was lower before and after the negotiation, mainly because negotiators bargaining online expected the other party to engage in distrustful behavior. This decrease in interpersonal trust online affected negotiators' desire for future interactions, also negatively affecting how satisfied they were with the negation process and the negotiated outcome. Köszegi and Kersten (2003) also showed that disputants' feeling of interpersonal trust and mutual understanding might be hampered in an online dispute resolution environment. In Köszegi and Kersten's study (2003), students took part in university courses to learn both offline and online negotiation skills. On the basis of their findings, Köszegi and Kersten (2003) argued that students found it difficult to discern others' intentions and to trust their counterpart when the negotiations were performed online, especially in conflicting situations. The authors further argued that dispute resolution online was difficult, because the negotiating students often misunderstood one another due to lack of transmission of non-verbal cues, such as their facial expressions or tone of voice. Altogether, these findings seem to suggest that the "leanness" of the online medium makes it hard for disputants to (re-)establish 
their mutual understanding and interpersonal trust; both important factors for the reestablishment of their relationship and the conflict's resolution.

The literature paints a contradictory picture with regard to the influence of computer-mediated communication (CMC) on the communication's effectiveness. On the one hand, studies argued that the lack of transmission of personal information in electronic media makes interpersonal communication (Kiesler 1986; Short et al. 1976) and the communication of trustworthiness (Fortune and Brodt 2000; Nadler 2001) difficult. It has been argued that the lack of interlocutors' physical co-presence (and subsequent perceived social presence; Croes et al. 2016) and the absence of or the reduced transmission of personal and social non-verbal cues in online communication channels (Kiesler and Sproull 1992) make it hard to detect and acknowledge emotions (e.g., Byron 2008; Goodman 2003). Moreover, it is believed that this absence of non-verbal communication increases the chance of miscommunication (Byron 2008; Cole and Blankley 2006), aggressive communication (Alonzo and Aiken 2004), deception (Valley et al. 1998), and competitive behavior (e.g., Wichman 1970). On the other hand, research has argued that communicators can overcome the cue-poor environment of electronic media by adapting their communication strategy (e.g., Antheunis et al. 2012) or by including additional cues to express affinity and emotions online (e.g., Walther et al. 2005). This adaptation might explain why communicators are able to successfully express their feelings and emotions online (e.g., Hine et al. 2009) and are even able to build valuable online social relationships (e.g., Antheunis et al. 2012; Croes et al. 2016).

Even though communicators are believed to be able to adapt their communicative style to the online environment, this does not imply that this adaptation always occurs, let alone be successful. That is, communicators are often overconfident about their ability to express themselves and to understand others (e.g., Savitsky et al. 2011; Van Boven et al. 2000), even when the access to non-verbal cues is limited (e.g., Byron 2008; Keysar and Henly 2002; Kruger et al. 2005). This overconfidence might be especially problematic in situations in which communicators' point of view differs, such as when communicators are in conflict (e.g., Eyal et al. 2018). More importantly, in text-based computer mediated communication, the communication exchange is far more ambiguous as interlocutors cannot rely on emotional displays or the behavioral context to interpret the exchange. This ambiguity stimulates interlocutors to rely on mindreading strategies that are known to hamper interpersonal accuracy (e.g., Ames 2005; Damen et al. 2020), such as using stereotypical information or by consulting their own perspective to intuit what others think, feel or desire. This stereotypical thinking or egocentric projection causes interlocutors to overestimate similarities and exaggerate differences between their own and others' viewpoints, inhibiting an accurate understanding of others' mental states (e.g., Ames 2005; Damen et al. 2020; Epley et al. 2004; Keysar 1994). Hence, taking a person's perspective seems to be quite challenging in computer-mediated communications in which communicators are designated to using inaccurate mindreading strategies.

Furthermore, communicators' lack of physical co-presence and visibility in text-based CMC negatively impacts their feelings of social presence and identifiability, both important factors that influence the formation and sustainment of 
interpersonal relations (e.g., Croes et al. 2016; see also Short et al. 1976). Knowing this, text-based CMC might also pose a challenge for mediation processes, especially for disputants' believe in their mediator's ability to guide them through the dispute. More specifically, with regard to the mediators' role, Katsh, Rifkin and Gaitenby (2000) have argued that in online mediations mediators are not able " (...) to set the parties at ease and create an environment for sustained problemsolving" (p. 714). Hence, it is believed that the loss of non-verbal cues in textbased conflict resolutions affects the transformative task of the mediator (Cole and Blankley 2006) and disables mediators to set a professional, understanding, and trustworthy mediation setting, which are both important for being able to reach a mutually satisfying solution (Beal 2000; Shah 2004).

In regard to the conflict's resolution, previous research states that online mediation sessions are most relevant for discussing impersonal issues in which nonverbal cues are less relevant (Cole et al. 1994; see also Culnan and Markus 1987). In addition, Yuan and his colleagues (2003) showed that mutual acceptance, understanding and trust were positively influenced by the addition of richer media compared to text conversations alone. The addition of audio- and video recordings increased levels of mutual trust and understanding. According to Yuan, Head and Du (2003), participants reported that the richer media increased the familiarity of their counterpart (see also Van der Toorn et al. 2015). Further, their research indicated that the richer media had a positive effect on the perceived outcome of the negotiation. However, others argue that this addition still does not compensate the real benefits of face-to-face communications and that "the subtleties of non-verbal communication are still lost in a webcam (...) session" (Victorio 2001, p. 293). Therefore, it is assumed that face-to-face mediation settings are more likely to reach more successful and mutually beneficial outcomes than online, text-based mediations (Thompson and Nadler 2002; Yuan et al. 2003).

In this study, we examine to what extent the communication mode affects the (re-)establishment of disputants' mutual understanding and interpersonal trust, and whether these important relationship factors affect the outcome of the intervention and disputants' satisfaction with the negotiated agreements. Following the argumentations of the previous discussed literature, we also expect that any effect of mediators' questioning style on disputants' attitude towards the mediation process will be affected by the mediations' mode of communication. More precisely, in contrast to offline, face-to-face mediations, we expect that online, text-based mediations negatively impact disputants' perspective-taking attempts (elicited by mediators' questioning style). Subsequently, we expect that this will negatively affect disputants' ability to restore feelings of interpersonal understanding and trust, and their belief in the mediator's ability to guide them successfully through the dispute's resolution. Therefore, we propose the following hypotheses:

H6 The communication mode of the intervention (online, face-to-face) will moderate the relationship between the type of questions the mediator uses (linear, circular) and disputants' (re-)established feelings of mutual understanding (H1ab) and interpersonal trust $(\mathrm{H} 1 \mathrm{~cd})$. The hypothesized relations are visualized in Fig. 1. 


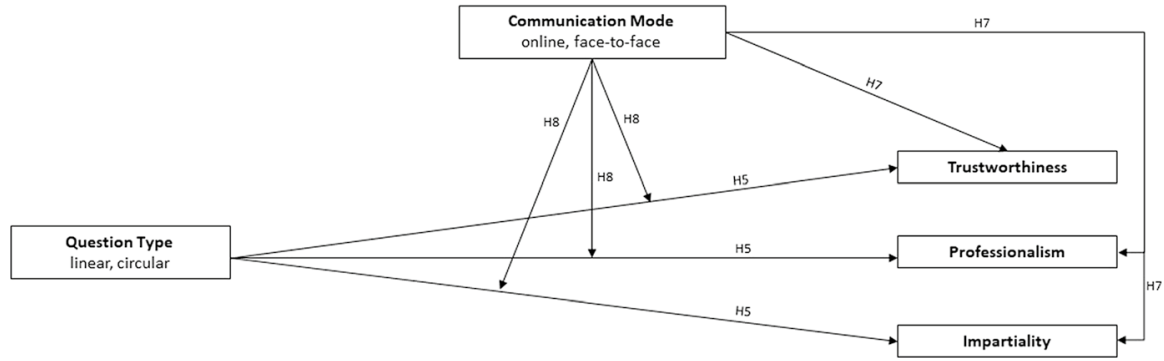

Fig. 2 Conceptual model of question type (linear, circular) predicting the evaluation of the mediator (trustworthiness, professionalism and impartiality), moderated by the communication mode of the intervention (online, face-to-face)

H7 Mediators will be found to be more trustworthy, professional and impartial in face-to-face than in online interventions. The hypothesized relationships are visualized in Fig. 2.

H8 The communication mode of the intervention (online, face-to-face) will moderate the relationship between the type of questions posed by the mediator (linear, circular) and the evaluation of the mediator (H5). The hypothesized relationships are visualized in Fig. 2.

\section{Method}

\subsection{Participants and Design}

A two-by-two design was used, with Communication Mode (online, face-to-face) and Question Type (linear, circular) as between subject factors. The effect of these factors on the dependent variables Conflict Resolution, Agreement Satisfaction, Agreement Integrativeness, and Evaluation of the Mediator was investigated. Eighty participants, all bachelor students from the department of Communication and Information Sciences at Tilburg University participated in the study and were randomly assigned to the conditions. Forty students participated in the face-toface interventions and in half of these interventions the mediator posed mainly circular questions $\left(N_{\text {male }}=4, N_{\text {female }}=16\right)$, whereas in the other half mediators asked mainly linear questions $\left(N_{\text {male }}=6, N_{\text {female }}=14\right)$. The age of the face-to-face participants ranged from 18 to 25 years $(M=21.83, S D=1.88)$. Out of the 40 students participating in the online sessions, 20 students were confronted with mainly circular questions $\left(N_{\text {male }}=7, N_{\text {female }}=13\right)$, and the other half with mainly linear questions $\left(N_{\text {male }}=7, N_{\text {female }}=13\right)$ during the intervention. The age of the participants in the online interventions ranged from 18 to 29 years $(M=21.33, S D=2.46)$. Students received course credits for their participation. 


\subsection{Confederates}

In each mediation setting, one participant and one confederate were invited. To control for the same initial trust and understanding levels of all participants, it was made sure that participants were not familiar with the confederate taking part in the study. In total ten different confederates (five males and five females) took part in the study. Out of these ten confederates, five were members of the university drama club. All confederates were trained to take part in the study and were instructed and trained to act consistently in all sessions. All confederates were paid $€ 5,-$ per session and played the role of the same neighbor in all sessions. In addition, one professional, $\mathrm{NMI}^{3}$-certified mediator (male) and two trained mediators (females) were invited to mediate the off- and online disputes. To guarantee the validity of the mediation sessions, the trained mediators followed a two-day NMI certified course in "Applying Mediation Skills".

\subsection{Procedure and Materials}

Before the mediation started, participants were invited in a separate room in which they could not meet the confederate. Participants in the online condition never met with their mediator or counterpart. These participants were asked to take place in a private computer-booth and were told to wait until the mediator would start the mediation. The online mediations took place in an online chat program that was specially designed for the study's purpose. In this program, disputants and the mediator were able to chat synchronously with one another in an online chat environment that only allowed disputants to communicate through written communication. Each chat message contained a label that specified the role of the communicator in the intervention (i.e., Mr./Ms. Jones, Mr./Ms. Smit, the mediator), and new messages were shown above the old ones so that the thread remained visible. An example of a chat conversation is provided in Fig. 3. Once all participants were settled, they were handed a conflict scenario of a neighbors' quarrel in which the participant was only confronted with the student's version of the conflict (Mr./Ms. Jones' perspective) and the confederate only with the neighbor's version (Mr./Ms. Smith's perspective). All participants were given enough time to read the scenario carefully and to empathize with the person they had to represent. Moreover, participants were told that they would be assisted by a mediator in helping them to reach a mutually beneficial solution for their dispute. After having read the scenarios, participants were told they had to negotiate with their neighbor, that they wanted to attain certain goals (described in the scenario), and that they also wanted to have a good relationship with their neighbor in the future, and that there was no time pressure. However,

\footnotetext{
${ }^{3}$ The Netherlands Mediation Institute (NMI) is a national mediation platform in the Netherlands that assures the quality of its registered mediators.
} 
Smith said on 09:17 am

Yes, that's correct.

Mediator said on 09:16 am

Is this the reason, Mr. Smith?

Jones said on 09:16 am

He is annoyed by the noise because he

has a full-time job that requires him to

be well rested.

Mediator said on 09:15 am

Ms. Jones, why do you think Mr. Smith is annoyed by the noise?

Fig. 3 An example of chat conversation in the online mediation condition. The mediator invites Ms. Jones to reason about Mr. Smith's perspective. The conversation should be read from the bottom to the top

when negotiations lasted more than thirty minutes, ${ }^{4}$ the experiment leader would ask the parties to wrap up the negotiation. After the initial instructions, participants in the face-to-face condition were asked to take place behind a table in the center of the room so that they could face their counterpart that would enter the room shortly after. The mediator would take place on the other side of the table, equally visible to both disputants. Since video-recordings were made of all face-to-face mediation sessions and all text conversations of the online mediations sessions were saved for later analysis, participants were asked to give their consent to making these recordings and using them for scientific purposes. No participant refused.

In the circular question conditions, mediators were instructed to pose mainly circular questions during the intervention, whereas mediators in the linear conditions were instructed to ask mainly linear questions to both participants and confederates. For instance in the linear conditions, the mediator would start by asking both parties: “(Mr/Ms) Jones/Smith, could you try to explain why you are here today?”. In the circular question condition, this question was formulated as "(Mr/Ms) Jones/ Smith, could you try to explain why the other person is here today?". After the mediation session, participants were asked to fill out a questionnaire. The questionnaire measured (1) whether a result was reached, (2) the satisfaction level of both parties with the outcome of the negotiation, (3) the understanding between parties

\footnotetext{
${ }^{4}$ Participants in the online mediations had fifty minutes to negotiate, because they had to type in their answers and had to read the reactions of the mediator and confederate.
} 
Table 1 Negotiated outcome divided into the sub constructs conflict resolution, agreement satisfaction and agreement integrativeness

\begin{tabular}{ll}
\hline Construct & Items \\
\hline Conflict resolution & Nominal data \\
& We have reached an outcome (yes/no) \\
Agreement satisfaction $\alpha=.80$ & 7-pointscale \\
I am satisfied with the outcome & I would have preferred another solution (R) \\
& The outcome disappoints me (R) \\
& 7-pointscale \\
Agreement integrativeness $\alpha=.69$ & The outcome is especially beneficial for \\
& me (R)* \\
The outcome is especially beneficial for the \\
other party (R) \\
The outcome is beneficial for both parties
\end{tabular}

$\alpha$ represents the Cronbach's Alpha of the items per construct. The $(\mathrm{R})$ signals that the scores were recoded before analyzing the results. *After excluding this item, the reliability of the scale improved from $\alpha=-.70$ to $\alpha=.69$

(before and after the mediation), (4) the interpersonal trust between parties (before and after the mediation), (5) the interpersonal trust during the mediation process, and the mediator's (6) trustworthiness, (7) professionalism and (8) perceived impartiality. All items were carefully developed for this study's purpose. To guarantee the validity of all our constructs, we examined the internal reliability and consistency of all scales, and reported the findings for each construct below.

\subsubsection{The Negotiated Outcome}

Participants indicated whether an agreement was reached (Conflict Resolution' $0=$ no agreement reached, $1=$ agreement reached). Furthermore, participants were asked to indicate how satisfied they were with this agreement by answering three declarative sentences (i.e., "I am satisfied with the outcome", "I would have preferred another solution $^{\mathrm{R}}$," "The outcome disappoints $\mathrm{me}^{\mathrm{R}}$ ") that were measured on a seven-point scale (Agreement Satisfaction; $1=$ not satisfied, $7=$ very satisfied). Further, participants were asked to indicate how mutually beneficial they perceived the solution to be. This was measured by asking participants to answer whether they thought the agreement was especially beneficial to themselves $(1=$ not especially beneficial for me, $7=$ especially beneficial for $\left.\mathrm{me}^{\mathrm{R}}\right)$, to the other $(1=$ not especially beneficial for the other party, $7=$ especially beneficial for the other party ${ }^{R}$ ), or equally beneficial to them and their counterpart $(1=$ not mutually beneficial, $7=$ very mutually beneficial). This resulted in the following constructs: Conflict Resolution, Agreement Satisfaction, and Agreement Integrativeness. All items were carefully developed for this study's purpose. Agreement Satisfaction contained three items and the scale had a high reliability, Cronbach's $\alpha=.80$. The reliability of Agreement Integrativeness was, however, very low due to one item examining the extent to which participants thought the outcome was especially beneficial to themselves. After excluding 
Table 2 Mutual understanding divided into the constructs feeling understood (before and after the intervention) and understanding (before and after the intervention)

\begin{tabular}{ll}
\hline Construct & Items \\
\hline Mutual understanding before intervention & \\
Feeling understood $\alpha=.83$ & 7-point scale \\
& To what extent did you feel understood by the other party? \\
& How well did the other party understand your feelings? \\
& How well did the other party understand your interests? \\
Understanding the other party $\alpha=.86$ & 7-pointscale \\
& To what extent did you understand the other party? \\
& How well did you understand the feelings of the other party? \\
& How well did you understand the other party's interests? \\
& To what extent do you think the other party has the feeling \\
& he/she is understood? \\
Mutual understanding after intervention & \\
Feeling understood $\alpha=.92$ & 7-point scale \\
& To what extent did you feel understood by the other party? \\
& How well did the other party understand your feelings? \\
& How well did the other party understand your interests? \\
& 7-pointscale \\
To what extent did you understand the other party? \\
How well did you understand the feelings of the other party? \\
How well did you understand the other party's interests? \\
To what extent do you think the other party has the feeling \\
he/she is understood?
\end{tabular}

$\alpha$ represents the Cronbach's Alpha of the items per construct

this item, the reliability of the scale drastically improved, Cronbach's $\alpha=.69$ (see Table 1).

\subsubsection{Mutual Understanding}

In addition, participants were asked to indicate on 14 seven-point newly developed scales how much they felt understood by their counterpart (Feeling Understood) and how much they understood their counterpart (Understanding), before and after the mediation $(1=$ not at all, $7=$ very much). All constructs had high reliabilities with Cronbach's $\alpha$ ranging from .83 to .92 . All items and their Cronbach's Alpha levels are presented in Table 2.

\subsubsection{Interpersonal Trust}

Participants were also asked to indicate for 21 items on a seven-point scale how much they thought they were trusted by their counterpart (Feeling Trusted) and how much they trusted their counterpart themselves (Trusting), before and after 
Table 3 Interpersonal trust divided into the constructs feeling trusted (before and after the intervention) and trusting (before and after the intervention)

\begin{tabular}{|c|c|}
\hline Construct & Items \\
\hline \multicolumn{2}{|l|}{ Interpersonal trust before intervention } \\
\hline Feeling Trusted by the other party $\alpha=.91$ & $\begin{array}{l}\text { 7-point scale } \\
\text { How well did the other party trust you? } \\
\text { To what extent did the other party think you were reliable? } \\
\text { To what extent did the other party think you were honest? }\end{array}$ \\
\hline Trusting the other party $\alpha=.82$ & $\begin{array}{l}\text { 7-pointscale } \\
\text { How well did you trust the other party? } \\
\text { To what extent did you think the other party was reliable? } \\
\text { To what extent did you think the other party was honest? }\end{array}$ \\
\hline \multicolumn{2}{|l|}{ Interpersonal trust after intervention } \\
\hline Feeling Trusted by the other party $\alpha=.88$ & $\begin{array}{l}\text { 7-point scale } \\
\text { How well did the other party trust you? } \\
\text { To what extent did the other party think you were reliable? } \\
\text { To what extent did the other party think you were honest? }\end{array}$ \\
\hline Trusting the other party $\alpha=.92$ & $\begin{array}{l}\text { 7-pointscale } \\
\text { How well did you trust the other party? } \\
\text { To what extent did you think the other party was reliable? } \\
\text { To what extent did you think the other party was honest? }\end{array}$ \\
\hline
\end{tabular}

$\alpha$ represents the Cronbach's Alpha of the items per construct. The $(\mathrm{R})$ signals that the scores were recoded before analyzing the results

the mediation $(1=$ not at all, $7=$ very much). For this scale, we adapted Naquin and Paulson's (2003) Organizational Trust Inventory-Short Form (OTI-SF) seven-point scale, ${ }^{5}$ so that it would be more appropriate for mediation settings. Both constructs had a high reliability as the Cronbach's $\alpha$ ranged from .82 to .92 . All items are presented in Table 3.

\subsubsection{Evaluation of the Mediator}

As a final step in the experimental procedure, disputants were asked to evaluate their mediator. Participants indicated on 7 newly developed seven-point scales how much they thought the mediator was trustworthy, professional and biased (i.e., partial). This resulted in the construction of the constructs Trustworthiness, Professionalism, and Impartiality. All constructs had a high reliability, with Cronbach's $\alpha$ ranging from .72 to .73 (see Table 4 for the individual items). Finally, after reporting their age and gender, participants were fully debriefed about the purpose of the study and thanked for their participation.

\footnotetext{
5 The OTI-SF was originally construed by Cummings and Bromiley's (1996) and later adapted by Naquin and Paulson (2003) to make it more appropriate for negotiations.
} 
Table 4 The evaluation of the mediator divided into the constructs trustworthiness, professionalism and partiality

Construct

Items

Evaluation of the mediator

Trustworthiness $\alpha=.73$

7-pointscale

The mediator was honest

I trusted the mediator

Professionalism $\alpha=.72$

7-point scale

The mediator was professional

The mediator was competent

The mediator was unfit (R)

Partiality $\alpha=.73$

7-point scale

The mediator did not show interest in the desires and needs of the other party (R)

The mediator listened to both parties equally

The mediator did not show interest in my desires and needs $(\mathrm{R})$

$\alpha$ represents the Cronbach's Alpha of the items per construct. The $(\mathrm{R})$ signals that the scores were recoded before analyzing the results

\section{Results}

We performed moderated mediation analyses using the PROCESS software of Hayes (2013). Each moderated mediation analysis focused on a different outcome variable of the intervention (i.e., Conflict Resolution, Agreement Satisfaction, Agreement Integrativeness). For the analyses, we followed the procedures developed by Hayes and Preacher (Hayes 2013; Hayes and Preacher 2014) and construed a moderated mediation model (model 7) for each outcome variable. For all models, we included Question Type $(0=$ linear, $1=$ circular $)$ as the predictor of the outcome variables: Conflict Resolution $(0=$ no outcome reached, $1=$ outcome reached), Agreement Satisfaction ( $1=$ not satisfied, $7=$ very satisfied) and Agreement Integrativeness ( $1=$ not at all beneficial for all parties involved, $7=$ very beneficial for all parties involved). In addition, all models included disputants' mutual understanding (Feeling Understood, Understanding) and interpersonal trust (Feeling Trusted, Trusting) as the mediating variables. Recall that participants reported their feelings of mutual understanding and interpersonal trust for both before and after the intervention. For our mediation analyses, we calculated the mean difference between participants' reported feelings from before to after the intervention and submitted these mean difference scores to our analyses. Higher mean difference scores indicated that disputants' mutual understanding (Feeling Understood, Understanding) and interpersonal trust (Feeling Trusted, Trusting) were higher after the intervention than before the intervention, whereas lower scores indicated this was not the case. Moreover, we entered the Communication Mode of the intervention $(0=$ online, $1=$ face-to-face $)$ as the moderator between Question Type and the different mediating variables. Predictors were centered before the analyses and the bootstrapped confidence intervals 


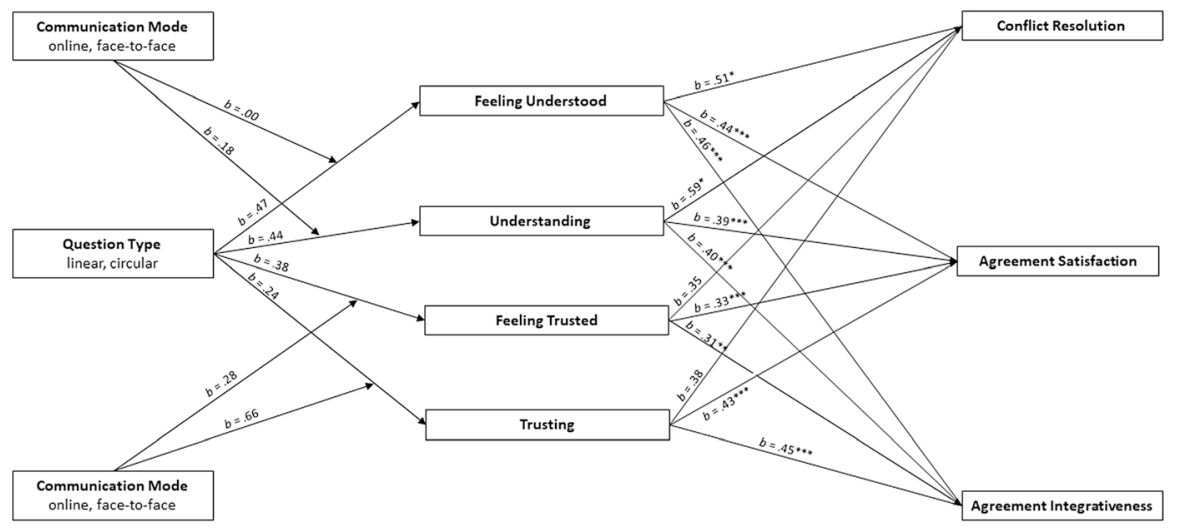

Fig. 4 The standardized regression coefficients for the moderated mediation model predicting conflict resolution, agreement satisfaction and agreement integrativeness from question type (linear, circular) via mutual understanding and Interpersonal Trust. Note: ${ }^{*} p<.05, * * p<.01$, *** $p<.001$

were obtained over 10.000 iterations. Furthermore, we additionally controlled for the influence of participants' and confederates' gender, as well as the mediator who had mediated the intervention, on our hypothesized relations by adding these three factors as covariates to all analyses. We reported the findings of the model that did not include these covariates when results showed that the covariates did not affect the outcome variable and/or our hypothesized relations. In the subsequent sections, we will discuss the findings for each outcome variable separately.

\subsection{Conflict Resolution}

The goal of this section was twofold. First, we examined the relationship between the type of questions used by the mediator (linear, circular) and the (re-)establishment of disputants' mutual understanding (H1ab) and interpersonal trust (H1cd). Secondly, we investigated the relationship between disputants' improved feelings of mutual understanding $(\mathrm{H} 2 \mathrm{a})$ and interpersonal trust $(\mathrm{H} 2 \mathrm{~b})$ on the likelihood of them finding a solution for their conflict (Fig. 1). We report the findings for each level of mutual understanding (Feeling Understood, Understanding) and interpersonal trust (Feeling Trusted, Trusted) separately. All findings remained unchanged when participants' and confederates' gender, and the mediator were entered as covariates to the analyses. Therefore, we report the effects of the moderated mediation models that did not include these covariates. The effects of all model variables are presented in Fig. 4.

\subsubsection{Feeling Understood}

We hypothesized that disputants would feel better understood by their counterpart after an intervention in which the mediator posed circular rather than linear questions (H1a). In addition, we expected that disputants' improved feelings of being 
understood would increase the likelihood of them finding a solution to their conflict (H2a). In contrast to our first hypothesis, the analysis did not reveal a direct effect of Question Type on Feeling Understood, $b=.47, S E=0.34, p=.168, t=-1.39,95 \%$ BCa CI $[-0.20,1.14]$. Participants' feeling of being understood by their counterpart did not depend on whether the mediator posed circular $\left(M_{\text {difference }}=2.53, S D=1.57\right)$ or linear questions $\left(M_{\text {difference }}=2.08, S D=1.51\right)$ during the intervention. However, results showed that hypothesis $\mathrm{H} 2 \mathrm{a}$ was supported by the data. There was a significant direct effect of Feeling Understood on Conflict Resolution, $b=.51, S E=0.21$, $p<.05, z=2.39,95 \%$ BCa CI [0.09, 0.92], indicating that as participants' feeling of being understood by their counterpart increased, so did the chance of disputants finding a solution for their conflict. Findings further revealed that there was no direct effect of Question Type on Conflict Resolution, $b=.29, S E=0.61, p=.632$, $z=-0.48,95 \%$ BCa CI $[-0.91,1.49]$, nor was there an indirect effect of Question Type on Conflict Resolution via Feeling Understood, $b_{\text {online }}=.24, S E=0.30,95 \%$ BCa CI $[-0.19,1.03] ; b_{\text {face-to-face }}=.24, S E=0.30,95 \%$ BCa CI $[-0.23,0.96]$.

We further hypothesized that the medium of the intervention would moderate the relationship between the question type used by the mediator and disputants' improved feeling of being understood (H6). Findings revealed a significant direct effect of Communication Mode on Feeling Understood, $b=1.09, S E=0.34$, $p<.01, t=3.22,95 \%$ BCa CI $[0.41,1.76]$, indicating that participants' feeling of being understood by their counterpart improved more from before to after the intervention when the intervention had taken place face-to-face $\left(M_{\text {difference }}=2.85\right.$, $S D=1.48)$ rather than online $\left(M_{\text {difference }}=1.77, S D=1.43\right)$. In contrast to H6, however, Question Type did not interact with Communication Mode on Feeling Understood, $b=.00, S E=0.67, p=.995, t=0.01,95 \%$ BCa CI $[-1.34,1.35]$. Hence, the difference in participants' feeling of being understood after circular and linear questions remained the same in both face-to-face $\left(M_{\text {difference linear }}=2.62, \mathrm{SD}=1.41\right.$; $\left.M_{\text {difference circular }}=3.09, \mathrm{SD}=1.56\right)$ and online interventions $\left(M_{\text {difference linear }}=1.53\right.$, $\mathrm{SD}=1.44 ; M_{\text {difference circular }}=2.00, \mathrm{SD}=1.42$ ).

\subsubsection{Understanding}

The analysis revealed a significant direct effect of Communication Mode on Understanding, $b=1.49, S E=0.30, p<.001, t=5.04,95 \%$ BCa CI $[0.90,2.08]$. Participants' Understanding improved more after the face-to-face intervention $\left(M_{\text {difference }}=2.65, S D=1.33\right)$ than after the online intervention $\left(M_{\text {difference }}=1.16\right.$, $S D=1.24)$. No significant direct effect was found of Question Type on Understanding, $b=.44, S E=0.30, p=.141, t=1.49,95 \%$ BCa CI $[-0.15,1.03]$, nor was the interaction between Question Type and Communication Mode significant, $b=.18, S E=0.59, p=.758, t=0.31,95 \%$ BCa CI $[-1.00,1.37]$. These findings indicated that $\mathrm{H} 1 \mathrm{~b}$ and $\mathrm{H} 6$ were not supported by the data. Participants' understanding of the other party did not improve more after circular $\left(M_{\text {difference }}=2.11\right.$, $\mathrm{SD}=1.61)$ than after linear questions $\left(M_{\text {difference }}=1.69, S D=1.32\right)$, and this pattern remained the same in both face-to-face $\left(M_{\text {difference linear }}=2.39, \mathrm{SD}=1.15\right.$; $\left.M_{\text {difference circular }}=2.92, \mathrm{SD}=1.47\right)$ and online interventions $\left(M_{\text {difference linear }}=0.99\right.$, $\left.\mathrm{SD}=1.10 ; M_{\text {difference circular }}=1.34, \mathrm{SD}=1.36\right)$. We further hypothesized that 
improved feelings of understanding the other party would increase the likelihood of disputants finding a solution to their conflict (H2a). Results confirmed this hypothesis by revealing a significant direct effect of Understanding on Conflict Resolution, $b=.59, S E=0.24, p<.05, z=2.48,95 \%$ BCa CI $[0.12,1.05]$. As participants' feeling of understanding the other party increased, so did their chance of them finding a solution for their conflict. There was no significant relationship, however, between Question Type and Conflict Resolution, $b=.35, S E=0.61, p=.567, z=0.57,95 \%$ BCa CI $[-0.85,1.55]$, nor was there a significant indirect effect of Question Type on Conflict Resolution via Understanding, $b_{\text {online }}=.21, S E=0.28,95 \%$ BCa CI $[-0.23$, 0.89]; $b_{\text {face-to-face }}=.31, S E=0.31,95 \%$ BCa CI $[-0.15,1.10]$.

\subsubsection{Feeling Trusted}

We hypothesized that the use of circular questions by the mediator would increase the disputants' feeling of being trusted by their counterpart, in comparison to the use of linear questions (H1c). The moderated mediation analyses showed that this hypothesis was not substantiated by the data. That is, Question Type did not have a direct effect on Feeling Trusted, $b=.38, S E=0.32, p=.246, t=1.17,95 \%$ BCa CI $[-0.26,1.01]$. Participants' improved feeling of being trusted was similar after both linear $\left(M_{\text {difference }}=2.32, S D=1.39\right)$ and circular questions $\left(M_{\text {difference }}=2.69\right.$, $S D=1.40$ ). We further hypothesized that participants' feeling of being trusted would increase the likelihood of them resolving their interpersonal conflict (H2b). Results showed that this hypothesis could not be confirmed. There was no significant direct effect of Feeling Trusted on Conflict Resolution, $b=.35, S E=0.21, p=.101$, $\mathrm{z}=1.64,95 \%$ BCa CI [ $-0.07,0.77]$. Participants' feeling of being trusted by the other disputant did not influence the chances disputants finding a solution for their conflict. Findings further showed that there was no direct effect of Question Type on Conflict Resolution, $b=.39, S E=0.60, p=.517, z=0.65,95 \%$ BCa CI $[-0.78$, 1.55], nor was there an indirect effect of Question Type on Conflict Resolution via Feeling Trusted, $b_{\text {online }}=.08, S E=0.18,95 \%$ BCa CI $[-0.17,0.56] ; b_{\text {face-to-face }}=.18$, $S E=0.23,95 \%$ BCa CI $[-0.13,0.90]$.

We further hypothesized that the communication mode of the intervention would moderate the relationship between question type and disputants' feeling of being trusted by their counterpart (H6). Results showed that this hypothesis was not supported by the data. Question Type did not interact with Communication Mode on Feeling Trusted, $b=.28, S E=0.64, p=.660, t=0.44,95 \%$ BCa CI $[-0.99,1.56]$. This finding indicated that participants' feeling of being trusted was similar after both circular and linear questions, and that this pattern remained the same in both face-to-face $\left(M_{\text {difference linear }}=2.42, S D=1.54 ; M_{\text {difference circular }}=2.93, S D=1.59\right)$ and online interventions ( $M_{\text {difference linear }}=2.22, S D=1.25 ; M_{\text {difference circular }}=2.45$, $S D=1.17$ ). Finally, findings showed that participants' feeling of being trusted did not differ as function of the Communication Mode of the intervention $\left(M_{\text {face-to-face }}=2.68, S D=1.57 ; M_{\text {online }}=2.33, S D=1.20\right)$, as there was no direct effect of Communication Mode on Feeling Trusted, $b=.34, S E=0.32, p=.290, t=1.07$, $95 \%$ BCa CI [-0.30, 0.98]. 


\subsubsection{Trusting}

Following hypothesis H1d, we expected that disputants' feeling of trust in the other party would increase more after the mediator had used circular rather than linear questions during the intervention. However, findings did not confirm this hypothesis as Question Type did not have a direct effect on Trusting, $b=.24, S E=0.34, p=.477$, $t=0.71,95 \%$ BCa CI $[-0.43,0.91]$. Trust in the other party was similar after an intervention that included linear $\left(M_{\text {difference }}=1.92, \mathrm{SD}=1.38\right)$ and circular $\left(M_{\text {difference }}=2.15\right.$, $\mathrm{SD}=1.65)$ questions. In addition, we hypothesized that participants' improved trust in the other party would positively influence the likelihood of them resolving their interpersonal conflict (H2b). Results showed, however, that the direct effect of Trusting on Conflict Resolution was only marginally significant, $b=.38, S E=0.20, p=.057$, $\mathrm{z}=1.90,95 \% \mathrm{BCa}$ CI $[-0.01,0.77]$. Hence, participants' improved trust in the other disputants tended to have a positive influence on disputants finding a solution for their conflict. In addition, results showed that there was no significant direct effect of Question Type on Conflict Resolution, $b=.44, S E=0.60, p=.463, \mathrm{z}=0.73,95 \%$ BCa CI $[-0.74,1.62]$, nor was there a significant indirect effect of Question Type on Conflict Resolution via Trusting, $b_{\text {online }}=-.03, S E=0.21,95 \%$ BCa CI $[-0.62,0.28]$; $b_{\text {face-to-face }}=.22, S E=0.24,95 \% \mathrm{BCa}$ CI $[-0.11,0.91]$.

We further hypothesized that the communication mode of the intervention would moderate the relationship between Question Type and disputants' improved feeling of trusting their counterpart (H6). Results showed that this hypothesis could not be confirmed. Communication Mode did not interact with Question Type on Trusting, $b=.66, S E=0.67, p=.334, t=0.97,95 \%$ BCa CI $[-0.69,2.00]$. The pattern between circular and linear questions remained the same in both face-to-face $\left(M_{\text {difference linear }}=2.22, S D=1.45 ; M_{\text {difference circular }}=2.79, S D=1.56\right)$ and online interventions $\left(M_{\text {difference linear }}=1.62, S D=1.27 ; M_{\text {difference circular }}=1.53, S D=1.54\right)$. Communication Mode did, however, have a direct effect on Trusting, $b=.92, S E=0.34$, $p=.008, t=2.75,95 \%$ BCa CI $[0.25,1.59]$, indicating that participants trusted their counterpart more after the face-to-face $\left(M_{\text {difference }}=2.50, S D=1.51\right)$ than the online $\left(M_{\text {difference }}=1.58, S D=1.39\right)$ intervention.

\subsection{Agreement Satisfaction}

We repeated the statistical procedure from the previous section and re-examined the relationship between the type of questions used by the mediator and disputants' improved feelings of mutual understanding (H1ab) and interpersonal trust (H1cd). More importantly, we investigated whether these improved feelings of mutual understanding $(\mathrm{H} 3 \mathrm{a})$ and interpersonal trust $(\mathrm{H} 3 \mathrm{~b})$ were related to a greater satisfaction with the negotiated agreement. For the clarity of this section, we only report the findings appertaining to our hypotheses $\mathrm{H} 3 \mathrm{a}$ and $\mathrm{H} 3 \mathrm{~b}$. All findings remained unchanged when participants' and confederates' gender, and the mediator were entered as covariates to the analyses. The effects of the moderated mediation models are, therefore, reported for the models that did not include these covariates. The effects of all model variables are displayed in Fig. 4. 


\subsubsection{Feeling Understood}

In line with $\mathrm{H} 3 \mathrm{a}$, results showed that Feeling Understood was positively related to Agreement Satisfaction, $b=.44, S E=0.8, p<.001, t=5.53,95 \%$ BCa CI $[0.28$, 0.59]. Participants were more satisfied with the negotiated agreement when they felt more understood by the other party. Findings further showed that there was no significant direct effect of Question Type on Agreement Satisfaction, $b=.12, S E=0.22$, $p=.567, t=0.58,95 \% \mathrm{BCa}$ CI $[-0.31,0.55]$, and that there was no significant indirect effect of Question Type on Agreement Satisfaction via Feeling Understood, $b_{\text {online }}=.20, S E=0.20,95 \%$ BCa CI $[-0.17,0.65] ; b_{\text {face-to-face }}=.21 S E=0.21,95 \%$ BCa CI [-0.19, 0.64].

\subsubsection{Understanding}

In line with our hypothesis $\mathrm{H} 3 \mathrm{a}$, results showed that Understanding was positively related to Agreement Satisfaction, $b=.39, S E=0.08, p<.001, t=5.10,95 \% \mathrm{BCa}$ CI $[0.24,0.55]$. Participants were more satisfied with the negotiated agreement when they felt they improved their understanding of their counterpart. Results further showed that the direct effect of Question Type on Agreement Satisfaction, $b=.16, S E=0.23, p=.494, t=0.69,95 \%$ BCa CI $[-0.30,0.61]$, and the indirect effect of Question Type on Agreement Satisfaction via Understanding, $b_{\text {online }}=0.14$, $S E=0.16,95 \%$ BCa CI $[-0.14,0.51] ; b_{\text {face-to-face }}=.21, S E=0.17,95 \%$ BCa CI $[-0.11,0.59]$, were both non-significant.

\subsubsection{Feeling Trusted}

In line with our hypothesis $\mathrm{H} 3 \mathrm{~b}$, results showed that Feeling Trusted was positively related to Agreement Satisfaction, $b=.33, S E=0.09, p<.001, t=3.53,95 \%$ BCa CI $[0.14,0.52]$. Findings further revealed that there was no significant relation between Question Type and Agreement Satisfaction, $b=.18, S E=0.25, p=.458, t=0.75$, 95\% BCa CI [-0.31, 0.67], and that the indirect effect of Question Type on Agreement Satisfaction via Feeling Trusted was absent, $b_{\text {online }}=.08, S E=0.13,95 \% \mathrm{BCa}$ CI $[-0.15,0.39] ; b_{\text {face-to-face }}=.17, S E=0.17,95 \%$ BCa CI $[-0.13,0.56]$.

\subsubsection{Trusting}

Trusting was positively related to Agreement Satisfaction, $b=.43, S E=0.08$, $p<.001, t=5.50,95 \%$ BCa CI [0.27, 0.58], thereby confirming H3b. Participants were more satisfied with the negotiated agreement when their trust in the other improved from before to after the intervention. Question Type did not have a direct effect on Agreement Satisfaction, $b=.23, S E=0.22, p=.300, t=1.04,95 \% \mathrm{BCa}$ CI [-0.20, 0.65], nor was there an indirect effect of Question Type on Agreement Satisfaction via Trusting, $b_{\text {online }}=-.04, S E=0.19,95 \%$ BCa CI $[-0.41,0.36]$; $b_{\text {face-to-face }}=.24, S E=0.21,95 \%$ BCa CI $[-0.17,0.66]$. 


\subsection{Agreement Integrativeness}

We hypothesized that participants' improved feelings of mutual understanding (H4a) and interpersonal trust (H4b) would be positively related to the perceived integrativeness of the negotiated outcome. In order to examine this hypothesis, we performed separate moderated mediation models that included Question Type as the predictor of Agreement Integrativeness, mediated by participants' improved feelings of mutual understanding (Feeling Understood, Understanding) and interpersonal trust (Feeling Trusted, Trusting). Since participants' and confederates' gender, and the mediator mediating the intervention did not affect our dependent variables nor our hypothesized relations, we report the effects of the moderated mediation models that did not include these covariates. In addition, we only report the findings that appertain to our hypotheses H4a and H4b. The models' effects are displayed in Fig. 4.

\subsubsection{Mutual Understanding}

In line with $\mathrm{H} 4 \mathrm{a}$, both Feeling Understood, $b=.46, S E=0.09, p<.001, t=4.84,95 \%$ $\mathrm{BCa}$ CI $[0.27,0.65]$, and Understanding, $b=.40, S E=0.10, p<.001, t=4.02,95 \% \mathrm{BCa}$ CI $[0.20,0.60]$, were positively related to Agreement Integrativeness. These findings indicated that participants perceived the negotiated agreement to be more beneficial for all parties involved as their feeling of being understood and understanding the other party increased. Analyses further revealed that there was no direct effect of Question Type on Agreement Integrativeness, $b_{\text {Feeling Understood }}=.07, S E=0.26, p=.776, t=0.29$, $95 \%$ BCa CI $[-0.44,0.58] ; b_{\text {Understanding }}=.11, S E=0.27, p=.684, t=0.41,95 \% \mathrm{BCa}$ CI $[-0.43,0.66]$. In addition, there was no indirect effect of Question Type on Agreement Integrativeness via Feeling Understood, $b_{\text {online }}=.21, S E=0.22,95 \%$ BCa CI $-0.17,0.69] ; b_{\text {face-to-face }}=.22, S E=0.22,95 \%$ BCa CI $[-0.20,0.68]$, nor via Understanding, $\left.b_{\text {online }}=.14, S E=0.17,95 \% \mathrm{BCa} C I-0.13,0.53\right] ; b_{\text {face-to-face }}=.22, S E=0.18$, $95 \%$ BCa CI $[-0.09,0.65]$.

\subsubsection{Interpersonal Trust}

Results showed that both Feeling Trusted, $b=.31, S E=0.11, p<.01, t=2.68,95 \% \mathrm{BCa}$ CI [0.08, 0.53], and Trusting, $b=.45, S E=0.09, p<.001, t=4.93,95 \%$ BCa CI [0.27, 0.64], were positively related to Agreement Integrativeness. Participants who trusted and felt more trusted after the intervention perceived the negotiated agreement to be beneficial for both parties involved. Analyses further showed that there was no direct effect of Question Type on Agreement Integrativeness, $b_{\text {Feeling Trusted }}=.20, S E=0.29$, $p=.499, t=0.68,95 \%$ BCa CI $[-0.38,0.78] ; b_{\text {Trusting }}=.18, S E=0.25, p=.482$, $t=0.71,95 \%$ BCa CI $[-0.32,0.68]$. There was also no indirect effect of Question Type on Agreement Integrativeness via Feeling Trusted, $b_{\text {online }}=.07, S E=0.13,95 \% \mathrm{BCa} C \mathrm{CI}$ $-0.15,0.40] ; b_{\text {face-to-face }}=.16, S E=0.17,95 \%$ BCa CI $[-0.10,0.61]$, nor via Trusting, $\left.b_{\text {online }}=-0.04, S E=0.21,95 \% \mathrm{BCa} C I-0.49,0.35\right] ; b_{\text {face-to-face }}=.26, S E=0.22,95 \%$ $\mathrm{BCa} \mathrm{CI}[-0.15,0.73]$. 


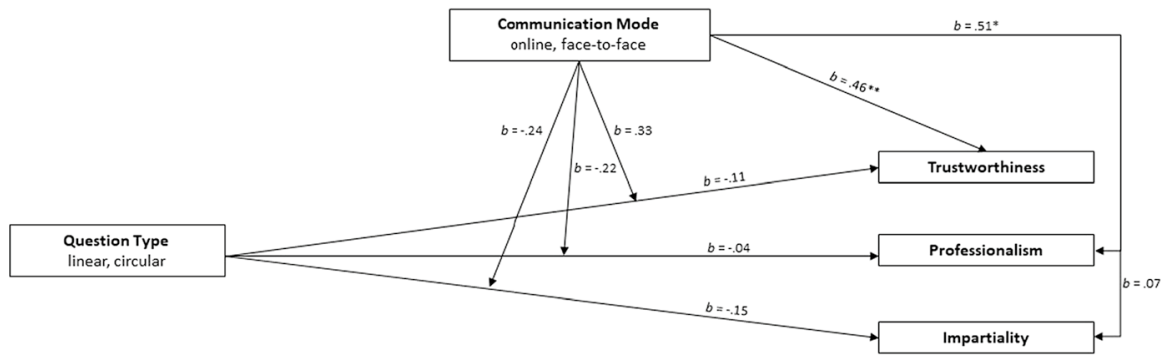

Fig. 5 The standardized regression coefficients for the moderation model predicting the perceived trustworthiness, professionalism and impartiality of the mediator from question type (linear, circular) moderated by communication mode (online, face-to-face). Note: $* p<.05$, $* * p<.01$

\subsection{Evaluation of the Mediator}

All mediators were evaluated with regard to their Trustworthiness, Professionalism and Impartiality. To examine whether the Communication Mode of the intervention (online, face-to-face) influenced how the mediator was evaluated by the disputants (H7), and whether the Communication Mode moderated the relationship between the type of questions used by the mediator and how the mediator was evaluated (H8), moderation analyses (model 1; Hayes 2013; Hayes and Preacher 2014) were performed for each of the three outcome variables (Trustworthiness, Professionalism and Impartiality). As a first step in the statistical procedure, we construed three models that all included Communication Mode as moderator between Question Type and Trustworthiness, Question Type and Professionalism, and Question Type and Impartiality. Secondly, to examine whether participants' and confederates' gender, as well as the mediator who had mediated the intervention, influenced our hypothesized relations, we added these three variables as covariates to all analyses. When the results showed that the covariates did not affect the outcome variable and/ or our hypothesized relations, we reported the findings of the model that did not include these covariates. The bootstrapped confidence intervals were obtained over 10.000 iterations. The effects of the moderation analyses are presented in Fig. 5.

\subsubsection{Trustworthiness}

In line with hypothesis $\mathrm{H} 7$, the analysis revealed a direct effect of Communication Mode on Trustworthiness, $b=.46, S E=0.17, p<.01, t=2.79,95 \% \mathrm{BCa}$ CI $[0.13,0.79]$. Participants trusted the mediator more in the face-to-face intervention $(M=6.23, S D=.63)$ than in the online intervention $(M=5.76, S D=.81)$. The direct effect of Question Type, $b=-.11, S E=0.17, p=.500, t=-0.68,95 \%$ BCa CI $-0.44,0.22]$, and the interaction between Question Type and Communication Mode, $b=.33, S E=0.33, p=.330, t=0.98,95 \%$ BCa CI [-0.34, 0.99], on Trustworthiness were both non-significant. This means that the mediators' perceived trustworthiness did not depend on whether mediators posed linear $(M=6.05, S D=.75)$ or circular 
questions $(M=5.94, S D=.76)$ during the mediation, and this pattern was similar in both the face-to-face $\left(M_{\text {linear }}=6.20, S D=.72 ; M_{\text {circular }}=6.25, S D=.55\right)$ and online interventions $\left(M_{\text {linear }}=5.90, S D=.77 ; M_{\text {circular }}=5.63, S D=.83\right)$. Hypotheses H5 and $\mathrm{H} 8$ were, therefore, not confirmed. All findings remained unchanged when we controlled for participants' and the confederates' gender, as well as for the mediator mediating the intervention.

\subsubsection{Professionalism}

The analysis revealed a significant direct effect of Communication Mode on the perceived Professionalism of the mediator, $b=.51, S E=0.22, p<.05, t=2.29,95 \% \mathrm{BCa}$ CI $[0.07,0.95]$. In line with hypothesis $\mathrm{H} 7$, mediators were perceived to be more professional in the face-to-face $(M=5.99, S D=0.86)$ than in the online $(M=5.48$, $S D=1.05)$ intervention. We further hypothesized that the type of questions used during the intervention would influence the mediator's perceived professionalism (H5). Results showed, however, that this hypothesis was not confirmed. Question Type did not have a significant effect on Professionalism, $b=-.04, S E=0.22$, $p=.851, t=-0.19,95 \% \mathrm{BCa}$ CI $[-0.48,0.40]$, indicating that participants thought the mediator was equally professional after both linear $(M=5.76, S D=1.00)$ and circular $(M=5.72, S D=0.97)$ questions. Findings further showed the interaction between Question Type and Communication Mode on Professionalism was nonsignificant, $b=-.22, S E=0.44, p=.626, t=-0.49,95 \%$ BCa CI $[-1.10,0.67]$. Our hypothesis that the Communication Mode of the intervention would moderate the relationship between Question Type and Professionalism (H8) was thereby not substantiated by the data. The relationship between Question Type and Professional remained the same in both face-to-face $\left(M_{\text {linear }}=6.07, \mathrm{SD}=.81 ; M_{\text {circular }}=5.92\right.$, $\mathrm{SD}=.92)$ and online $\left(M_{\text {linear }}=5.45, \mathrm{SD}=1.10 ; M_{\text {circular }}=5.52, S D=1.01\right)$ mediations. The findings remained unchanged when we controlled for the gender of the participant and the confederate, and for the mediator mediating the intervention.

\subsubsection{Impartiality}

After entering the participants' and confederate's gender, and the mediator who mediated the interventions as covariates, we found a significant effect of Participants' Gender on the perceived Impartiality of the mediator, $b=-.59, S E=0.24, p=.015$, $t=-2.48,95 \%$ BCa CI [ $-1.02,0.54]$. Overall, women $(M=6.34, S D=0.75)$ found their mediator to be more impartial than men $(M=5.82, S D=0.98)$. Covariate Mediator did not have a direct effect on Impartiality, $b=-.14, S E=0.13, p=.296$, $t=-1.05,95 \%$ BCa CI $[-0.39,0.12]$, indicating that all three mediators were perceived to be equally impartial $\left(M_{\text {mediator } 1}=6.29, S D=0.93 ; M_{\text {mediator } 2}=6.28\right.$, $\left.S D=0.62 ; M_{\text {mediator } 3}=6.02, S D=0.95\right)$. Furthermore, Confederates' Gender $(M$ male $\left.=6.10, S D=0.92 ; M_{\text {female }}=6.27, S D=0.79\right)$ did not have a direct effect on the perceived Impartiality of the mediator, $b=.29, S E=0.20, p=.159, t=1.42,95 \%$ BCa CI [-0.11, 0.67]. We hypothesized that participants would perceive their mediator to be less partial after an intervention in which circular rather than linear questions were used (H5). Findings showed, however, that this hypothesis 
could not be confirmed. Participants thought that their mediator had been equally partial after both linear $(M=6.24, S D=0.66)$ and circular $(M=6.13, S D=1.02)$ questions, $b=-.15, S E=0.20, p=.447, t=-0.76,95 \%$ BCa CI $[-0.55,0.25]$. In addition, we expected that mediator would be perceived to be more partial in the online than in the face-to-face interventions (H7), but our results showed that this hypothesis was not substantiated by the data. Participants thought their mediator had been equally partial in both face-to-face $(M=6.25, S D=0.84)$ and online $(M=6.12$, $S D=0.88)$ interventions, $b=.07, S E=0.20, p=.735, t=0.34,95 \%$ BCa CI $[-0.33$, 0.46]. Moreover, Question Type did not interact with Communication Mode on Impartiality, $b=-.24, S E=0.39, p=.544, t=-0.61,95 \%$ BCa CI [-1.02, 0.54], thereby not confirming H8. The perceived Impartiality of the mediator after linear and circular questions remained the same in face-to-face $\left(M_{\text {linear }}=6.35, S D=.62\right.$; $\left.M_{\text {circular }}=6.15, S D=1.03\right)$ and online $\left(M_{\text {linear }}=6.13, S D=.70 ; M_{\text {circular }}=6.10\right.$, $S D=1.04)$ interventions.

\section{General Discussion}

This study examined the influence of disputants' perspective-taking on restoring their relationship and resolving their interpersonal conflict in online and offline mediations. We addressed the question whether the mediator's use of circular questions-a perspective-taking technique-would improve disputants' feelings of mutual understanding and interpersonal trust during both online and face-to-face interventions. We examined this question by asking disputants to take part in negotiation sessions that were facilitated by a professional mediator.

We hypothesized that the use of circular questions by the mediator during the intervention would help disputants to improve their feelings of mutual understand and interpersonal trust to a higher degree than the use of linear questions. In contrast to our expectations, our findings showed that the type of questions used by the mediator did not influence the extent to which disputants' improved their feeling of understanding and trust from before to after the intervention. Our findings did show, however, that disputants' restored feelings of mutual understanding did predict whether disputants found a solution for their interpersonal conflict. In line with our expectation, disputants were more likely to reach a solution for their conflict if they felt more understood and understood their counterpart more after the intervention. Interestingly, disputants' improved feelings of interpersonal trust did not predict whether disputants reached an agreement. Whether disputants reached an agreement was not depending on whether they trusted the other party more or felt more trusted by the other party after the intervention.

Moreover, we expected that restored feeling of understanding and trust would positively influence disputants' satisfaction with the negotiated agreement. In line with our expectations, our findings showed disputants were more satisfied with the negotiated agreement and perceived the agreement to be more integrative if their feelings of understanding and trust improved from before to after the intervention. Higher improvements in disputants' feelings of trust and understanding resulted in disputants perceiving the agreement to be more beneficial for all parties involved. 
We further examined the extent to which the communication mode of the intervention (online, face-to-face) influenced disputants' improved of feelings of mutual understand and trust. Our findings showed that disputants felt more understood, and understood and trusted the other party more after face-to-face interventions than online interventions. Our findings further showed that disputants' improved feeling of being trusted by the other party was not affected by the communication mode of the intervention. For both face-to-face and online mediations, disputants felt that the other party learned to trust them better to the same degree.

Finally, we examined the extent to which the type of questions used by the mediator and the communication mode of the intervention would affect how disputants would evaluate their mediator. We hypothesized that the use of circular questions by the mediator would cause disputants to evaluate the mediator more positively than when the mediator only posed linear questions during the intervention. In contrast to our expectation, however, disputants perceived the mediator to be equally trustworthy, professional and impartial after the use of circular and linear questions. Furthermore, in line with our expectations, disputants perceived their mediator to be more trustworthy and professional in the face-to-face than in the online interventions. However, the communication mode of the intervention did not affect the mediator's perceived impartiality. Mediators were perceived to be equally impartial in both face-to-face and online mediations.

One important finding of our study is that the online communication mode influenced disputants' perceptions of their counterpart, mediator and the mediation process. Since mutual understanding and interpersonal trust resulted in more satisfying and more integrative negotiated agreements, it is important to acknowledge the effect the "cue-poor" environment of the online medium can have on disputants' rapport building. Our findings support previous research arguing that communication channels that only allow a reduced transmission of non-verbal and paralinguistic cues make it difficult for disputants to learn to trust and to understand one another (e.g., Köszegi and Kersten 2003; Van der Toorn et al. 2015; Yuan et al. 2003), and that these cue-poor communication channels can affect how competent and trustworthy the mediator is perceived to be (e.g., Cole and Blankley 2006; Druckman et al. 2004; Yuan et al. 2003). In our study, the online interventions took place via synchronous chat conversations through which disputants were only able to communicate via written text. We encourage future research to examine the extent to which the addition of non-verbal and paralinguistic cues affecting disputants' feelings of social presence and identifiability (Croes et al. 2016) — such as disputants' and mediators' facial expressions or tone of voice (e.g., Yuan et al. 2003) —in online interventions contribute to disputants' rapport building and, as a consequence, to the dispute's resolution. In addition, research has shown that negotiation support systems can increase the amount and quality of the communication between online negotiators (e.g., Dannenman and Schoop 2011; Schoop et al. 2014), thereby helping negotiators to focus on relational factors alongside the negotiation. Hence, future research might investigate the extent to which negotiation support systems can reduce the negative influence of the cue-poor communication channel on the conflict's resolution. 
This study showed that the circular questions used by the mediator did not affect the amendment of disputants' mutual understanding and interpersonal trust, nor did it affect disputants' evaluation of the mediator. Circular questions did not seem to have a more positive influence on the mediation process than linear questions. Although the use of the circular question is argued to facilitate communicator's understanding of each other's point of view (e.g., Choy 2005; Putnam 2004; Tomm 1985; Wilkinson 1992), our study did not find a direct relationship between the circular question and disputants' enhanced understanding. However, we did find that mutual understanding and interpersonal trust influenced the negotiated agreement. Not only did disputants reach more settlements that were integrative in nature, disputants were also much happier with the settlements they reached when they understood their counterpart better, and when they felt more understood and trusted by their counterpart. Hence, these findings indicate the importance of establishing mutual understanding and trust during mediation processes (e.g., Boca et al. 2018; Deutsch et al. 2006; Herrman 2009). Here, we propose two important factors that could have contributed to mediators' questioning style not directly affecting disputants' feelings of interpersonal trust and understanding. First, we believe that the timing of the circular question is an important aspect that can influence disputants' actual perspective-taking behavior. For disputants to take over their interlocutor's point of view, the mediator has to ask the circular question at the right moment in time. If a mediator asks a circular question too early in the process, then disputants will - reluctantly - answer the question, because they are not ready to take over the perspective of their counterpart yet. To the other party, this can come across as a forced understanding (Wilkinson 1992; Prein 2007) and it may hamper disputants' feeling of being understood or even be counterproductive. We analyzed the first five minutes of a five random mediation sessions and found three answer styles to the circular question. We found that a circular question could be accepted (i.e., the receiver of the question accepts that he or she is forced to take over the perspective of his or her counterpart) or rejected (i.e., the receiver resists in taking over the perspective of his or her counterpart). More importantly, we also found the occurrence of forced circular questions. In these occasions, the receiver takes over the perspective of the other person, but does it reluctantly and not genuinely. For instance, a mediator can ask Mary to imagine how John feels about the noise late at night, and Mary might answer in the line of "(...) disturbed, I guess. However, John just does not know what it is like to have fun". This answer style does not have the same effect as an accepted answer style and may hamper the improvement of parties' feelings of trust and understanding. A secondary factor that might have played a role here is that we measured interlocutors' subjective feelings of trust and understanding using self-reported measures to capture these perceived feelings of change. Even though these subjective measures indicate interlocutors' attitude towards their own and their interlocutor's perspective-taking behavior, we know that these self-reports do not always match with perceivers' actual perspective-taking performance (Damen 2020; see also Davidson et al. 2020; Faber et al. 2018; Kaye et al. 2020; Vanden Abeele et al. 2013 on the disadvantage of using self-report measures). Subjective measures are highly susceptible to perceivers' overconfidence in their ability to assess their own (and others') behavior, and might decrease in hindsight due to their 
interlocutor's behavioral stance or reluctance to reciprocate. To know the extent to which the circular questioning style affects interlocutors' actual perspective-taking attempts, future research might explore disputants' physical and verbal reactions to these different answer styles, thereby combining both subjective and objective measures to measure disputants' perspective-taking.

Future research might address the above-mentioned issues by adjusting the experimental method. For instance, future research could examine the perception of mutual understanding and interpersonal trust in a more quantitative manner, byfor example-letting participants read and interpret different mediation scenario's in which linear versus circular questions are used by a mediator. In this way, the communicative style of the mediator is examined in a vacuum, thereby limiting the possible influence of other questioning techniques (such as summarizing, paraphrasing, or reflecting) that could have be used alongside the manipulated questioning style by the mediator in our staged interventions.

Conversely, the use and the effects of the circular question on conflict resolution could also be examined in real life interventions, thereby taking a qualitative approach to investigate disputants' responses to the circular questions posed by the mediator. We encourage future research to undertake this qualitative approach, as it contributes to the generalizability of the research findings. In turn, this approach allows for a more detailed examination as to whether and how the mediator's questioning style affects the overall quality of disputants' communication in both offline and online interventions (e.g., Schoop et al. 2010; Weigand et al. 2003). Furthermore, this study randomly distributed 80 participants to the four treatment groups, resulting in 20 participants per condition. As small sample sizes might pose challenges for estimating the accuracy of the effects (e.g., Lakens and Evers 2014), we encourage future research to considering enlarging the sample size of the study.

Finally, future studies might investigate the role the mediator's and disputants' affective feelings and displays play in disputants' rapport building during both offline and online interventions. Ample research has shown that the expression and perception of emotion can influence negotiation processes (e.g., Anderson and Thompson 2004; Hine et al. 2009; Kopelman et al. 2006; Van Kleef et al. 2004, 2006), thereby influencing communicators' ability to engage in perspective-taking (e.g., Todd et al. 2015). Since we did not examine the effect of the circular question on these types of (non-)verbal displays, it is interesting to investigate whether the mediator's communicative style influences the emotional display of disputants and the extent to which these displays influence disputants' rapport building.

\section{Conclusion}

By comparing offline and online mediation sessions, this study showed that disputants' rapport building during the intervention predicted how satisfying they perceived the negotiated agreement to be. When disputants were able to improve their feelings of mutual understanding and interpersonal trust from before to after the mediation, they were more likely to perceive the negotiated agreement to be satisfying and integrative. This study further showed that the online communication 
channel negatively affected disputants' rapport building and their evaluation of the mediator. That is, disputants negotiating in the offline interventions improved their feelings of understanding and trust to a larger degree than the disputants negotiating in the online, chat interventions. Disputants also perceived the live (offline) mediator to be more professional and trustworthy than the e-mediator. Findings further showed that communication style of the mediator did not affect disputants' feelings of understanding and trust. The extent to which disputants felt they improved their mutual understanding and interpersonal trust from before to after the mediation did not depend on whether mediators had posed mainly circular or linear questions during the intervention.

\section{Compliance with Ethical Standards}

Conflict of interest The authors declare that they have no conflict of interest.

Ethical Approval The research was conducted conform the ethical guidelines set by the ethical committee of the Tilburg School of Humanities and Digital Sciences at Tilburg University.

Informed Consent All participants gave their informed consent before participating in the study.

Open Access This article is licensed under a Creative Commons Attribution 4.0 International License, which permits use, sharing, adaptation, distribution and reproduction in any medium or format, as long as you give appropriate credit to the original author(s) and the source, provide a link to the Creative Commons licence, and indicate if changes were made. The images or other third party material in this article are included in the article's Creative Commons licence, unless indicated otherwise in a credit line to the material. If material is not included in the article's Creative Commons licence and your intended use is not permitted by statutory regulation or exceeds the permitted use, you will need to obtain permission directly from the copyright holder. To view a copy of this licence, visit http://creativecommons.org/licen ses/by/4.0/.

\section{References}

Adams JF (1997) Questions as interventions in therapeutic conversation. J Fam Psychother 8:17-35

Alonzo M, Aiken M (2004) Flaming in electronic communication. Decis Support Syst 36:205-213

Ames DR (2005) Everyday solutions to the problem of other minds: which tools are used when? In: Malle BF, Hodges SD (eds) Other minds: how humans bridge the divide between self and others. The Guilford Press, New York, pp 158-173

Anderson C, Thompson LL (2004) Affect from the top down: how powerful individuals' positive affect shapes negotiations. Org Behav Hum Decis Process 95(2):175-187

Antheunis ML, Schouten AP, Valkenburg PM, Peter J (2012) Interactive uncertainty reduction strategies and verbal affection in computer-mediated communication. Commun Res 39(6):757-780. https:// doi.org/10.1177/0093650211410420

Batson CD, Chang J, Orr R, Rowland J (2002) Empathy, attitudes, and action: can feeling for a member of a stigmatized group motivate one to help the group? Pers Soc Psychol B 28:1656-1666

Beal BL (2000) Online mediation: has its time come? Ohio State J Disput Resolut 15:735-737

Bichler M, Kersten G, Strecker S (2003) Towards a structured design of electronic negotiations. Group Decis Negot 12:311-335

Boca S, Garro M, Giammusso I, Scaffidi Abbate C (2018) The effect of perspective taking on imitation. Psychol Res Behav Manag 11:411-416 
Brandon M (2011) Questioning our questions-expanding facilitative dispute resolution questioning techniques. ADR Bull 12:1-5

Brenninkmeijer AFM, Bonenkamp HJ, van Oyen K, Prein HCM (2009) Handboek mediation (4 ${ }^{\mathrm{e}}$ druk). Sdu Uitgevers, Den Haag

Brown J (1997) Circular questioning: an introductory guide. A.N.Z.J. Fam Ther 18:109-114

Brown JM (2010) The Milan principles of hypothesising, circularity and neutrality in dialogical family therapy: extinction, evolution, eviction...or emergence? ANZJFT 31:248-285

Butler JK Jr (1999) Trust expectations, information sharing, climate of trust, and negotiation effectiveness and efficacy. Group Org Manag 24(2):217-238

Byron K (2008) Carrying to heavy a load? Communication and miscommunication of emotion by email. Acad Manag Rev 33(2):309-327

Carnevale PJ, Arad S (1996) Bias and impartiality in international mediation. In: Bercovitch J (ed) Resolving international conflicts: the theory and practice of mediation. Lynne Rienner Publishers Inc, USA, pp 39-54

Cecchin G (1987) Hypothesizing, circularity, and neutrality revisited: an invitation to curiosity. Fam Proc 26:405-413

Chandler MJ (1973) Egocentrism and antisocial behavior: the assessment and training of social perspective-taking skills. Dev Psychol 9(3):326-332

Choy J (2005) De vraag op het antwoord: systemische interventies voor conflicten in organisaties. NISTO Publicaties, Santpoort Zuid

Clark HH, Brennan S (1993) Grounding in communication. In: Resnick LB, Levine JM, Teasley SD (eds) Perspectives on socially shared cognition. American Psychological Association, Washington, DC, pp 127-149

Clark HH, Carlson T (1982) Hearers and speech acts. Language 58:332-373

Clore GL, Jeffery KM (1972) Emotional role playing, attitude change, and attraction toward a disabled person. J Pers Soc Psychol 23(1):105-111

Cole SR, Blankley KM (2006) Online mediation: where we have been, where we are know, and where we should be. U Toledo Law Rev 38:193-212

Cole SR, McEwen CA, Rogers NH (1994) Mediation: law, policy, practice, 2nd edn. Clark Boardman Callaghan, Deerfield

Croes EAJ, Antheunis ML, Schouten AP, Krahmer EJ (2016) Teasing apart the effect of visibility and physical co-presence to examine the effect of $\mathrm{CMC}$ on interpersonal attraction. Comput Hum Behav 55:468-476

Crook CW, Booth R (1997) Building rapport in electronic mail using accommodation theory. Adv Manag J 62:4-14

Cummings LL, Bromiley P (1996) The organizational trust inventory (OTI): development and validation. In: Kramer RM, Tyler TR (eds) Trust in organizations: frontiers of theory and research. Sage, Thousand Oaks, pp 302-330

Culnan MJ Marcus ML (1987) Information technologies. In: FM Jablin, LL Putnam, KH Roberts, LW Porter (Eds), Handbook of organizational communications: an interdisciplinary perspective, Sage, Newbury Park, pp 420-43

Damen D (2020) Taking perspective in communication: exploring what it takes to change perspectives. Doctoral dissertation, Tilburg University

Damen D, Van der Wijst P, Van Amelsvoort M, Krahmer E (2020) Can the curse of knowing be lifted? The influence of explicit perspective-focus instructions on readers' perspective-taking. J Exp Psychol Learn Memory Cognit. Advance online publication. https://doi.org/10.1037/xlm0000830

Dannenman A, Schoop M (2011) Conflict resolution support in electronic negotiations. In: A Bernstein, G Schwabe (eds) Proceedings of the 10th international conference on Wirtschaftsinformatik, vol 2, Zurich, Switzerland

Davidson BI, Shaw H, Ellis DA (2020) Fuzzy constructs in assessment: the overlap between mental health and technology 'use'. https://doi.org/10.31234/osf.io/6durk

Davis MH (1996) Empathy a social psychological approach. Westview Press, Boulder

Davis MH, Conklin L, Smith A, Luce C (1996) Effect of perspective taking on the cognitive representation of persons: a merging of self and other. J Pers Soc Psychol 70:713-726

Deutsch M (1958) Trust and suspicion. J Confl Resolut 2(4):265-279

Deutsch M (2006) Cooperation and competition. In: Deutsch M, Coleman PT, Marcus EC (eds) The handbook of conflict resolution: theory and practice, 2nd edn. Jossey-Bass, San Francisco 
Deutsch M, Coleman PT, Marcus EC (2006) The handbook of conflict resolution: theory and practice. Jossey-Bass, San Francisco

Diorinou M, Tseliou E (2014) Studying circular questioning "in situ": discourse analysis of a first systemic family therapy session. J Marital Fam Ther 40:106-121

Druckman D, Harris R, Ramberg B (2002) Computer-assisted international negotiation: a tool for research and practice. Group Decis Negot 11(3):231-256

Druckman D, Duckman JN, Arai T (2004) E-mediation: evaluating the impacts of an electronic mediator on negotiating behavior. Group Decis Negot 13:481-511

Druckman D, Mitterhofer R, Filzmoser M, Koeszegi ST (2014) Resolving impasses in e-negotiation: does e-mediation work? Group Decis Negot 23:193-210. https://doi.org/10.1007/s10726-013-9356-4

Epley N, Keysar B, Van Boven L, Gilovich T (2004) Perspective taking as egocentric anchoring and adjustment. J Pers Soc Psychol 87(3):327-339. https://doi.org/10.1037/0022-3514.87.3.327

Evans AM, Krueger JI (2011) Elements of trust: risk and perspective-taking. J Exp Soc Psychol 47:171-177

Eyal T, Steffel M, Epley N (2018) Perspective mistaking: Accurately understanding the mind of another requires getting perspective, not taking perspective. J Pers Soc Psychol 114(4):547-571

Faber M, Bixler R, D’Mello SK (2018) An automated behavioral measure of mind wandering during computerized reading. Behav Res Methods 50(1):134-150

Falk DR, Johnson DW (1977) The effects of perspective-taking and egocentrism on problem solving in heterogeneous and homogeneous groups. J Soc Psychol 102:63-72

Fett AKJ, Shergill SS, Gromann PM, Dumontheil I, Blakemore SJ, Yakub F, Krabbendam L (2014) Trust and social reciprocity in adolescence-a matter of perspective-taking. J Adolesc 37:175-184

Fleuridas C, Nelson T, Rosenthal C (1986) The evolution of circular questions. J Marriage Fam Ther 12:113-127

Fortune A, Brodt SE (2000) Face-to-face or virtually, for the second time around: the influence of task, past experience, and media on trust and deception in negotiation. In: The academy of management annual conference, Toronto, Ontario, Canada

Galinsky AD, Moskowitz GB (2000) Perspective-taking: decreasing stereotype expression, stereotype accessibility, and in-group favoritism. J Pers Soc Psychol 78(4):708-724

Galinsky AD, Mussweiler T (2001) First offers as anchors: the role of perspective-taking and negotiator focus. J Pers Soc Psychol 81:657-669

Galinsky AD, Ku G, Wang CS (2005) Perspective-taking and self-other overlap: fostering social bonds and facilitating social coordination. Group Process Intergr 8(2):109-124

Galinsky AD, Maddux WW, Gilin D, White JB (2008a) Why it pays to get inside the head of your opponent in negotiations. Psychol Sci 19(4):378-384

Galinsky AD, Maddux WW, Gilin D, White JB (2008b) Why it pays to get inside the head of your opponent: the differential effects of perspective taking and empathy in negotiations. Psychol Sci 19:378-384

Galinsky AD, Gilin D, Maddux WW (2011) Using both your head and your heart: the role of perspective taking and empathy in resolving social conflict. In: Forgas JP, Kruglanski AW, Williams KD (eds) The psychology of social conflict and aggression. Psychology Press, New York, pp 103-118

Gambetta D (1988) Trust: making and breaking cooperative relations. Basil Blackwell, New York

Gattiker TF, Huang W, Schwarz JL (2007) Negotiation, email, and Internet reverse auctions: how sourcing mechanisms deployed by buyers affect suppliers' trust. J Oper Manag 25(1):184-202

Giammarco EA, Vernon PA (2014) Vengeance and the dark triad: the role of empathy and perspective taking in trait forgiveness. Pers Indiv Differ 67:23-29

Goldstein NJ, Vezich IS, Shapiro JR (2014) Perceived perspective taking: when others walk in our shoes. J Pers Soc Psychol 106(6):941-960

Goodman JW (2003) The pros and cons of online dispute resolution: an assessment of cyber-mediation websites. Duke Law Technol Rev 2:1-16

Hayes AF (2013) Introduction to mediation, moderation, and conditional process analysis: a regressionbased approach. Guilford Publications Inc, New York

Hayes AF, Preacher KJ (2014) Statistical mediation analysis with a multicategorical independent variable. Br J Math Stat Psychol 67(3):451-470

Herrman MS (ed) (2009) The Blackwell handbook of mediation: bridging theory, research, and practice. Wiley, Malden

Hine MJ, Murphy SA, Weber M, Kersten G (2009) The role of emotion and language in dyadic e-negotiations. Group Decis Negot 18(3):193-211 
Husnu S, Crisp RJ (2015) Perspective-taking mediates the imagined contact effect. Int J Intercult Rel 44:29-34

Johnson DW (1971) Role reversal: a summary and review of the literature. Int J Group Tens 1:318-334

Johnson DW (1975) Cooperativeness and social perspective taking. J Pers Soc Psychol 31:241-244

Kalff S, Uitslag M (2007) The ins and outs of mediation. HU Mediation, Utrecht

Katsh E, Rifkin J, Gaitenby A (2000) E-commerce, E-disputes, and E-dispute resolution: in the shadow of "eBay Law". Ohio State J Disput Resolut 15:705-734

Kaye LK, Orben A, Ellis DA, Hunter SC, Houghton S (2020) The conceptual and methodological mayhem of "screen-time". https://doi.org/10.31219/osf.io/u4hqn

Kee HW (1970) The development, and the effects upon bargaining, of trust and suspicion. Dissertation, University of Britisch Columbia

Keysar B (1994) The illusory transparency of intention: Linguistic perspective taking in text. Cognit Psychol 26:165-208

Keysar B, Henly AS (2002) Speakers' overestimation of their effectiveness. Psychol Sci 13(3):207-212

Kiesler S (1986) The hidden messages in computer networks. Harv Bus Rev 64:46-58

Kiesler S, Sproull L (1992) Group decision making and communication technology. Organ Behav Hum Dec 52:96-123

Kimmel MJ, Pruitt DG, Magenau JM, Konar-Goldband E, Carnevale PH (1980) Effects of trust, aspiration and gender on negotiation tactics. J Pers Soc Psychol 38:9-23

Kopelman S, Rosette AS, Thompson L (2006) The three faces of Eve: strategic displays of positive, negative, and neutral emotions in negotiations. Organ Behav Hum Decis Process 99:81-101

Köszegi S, Kersten G (2003) On-line/off-line: joint negotiation teaching in Montreal and Vienna. Group Decis Negot 12:337-345

Kruger J, Epley N, Parker J, Ng Z (2005) Egocentrism over e-mail: can we communicate as well as we think? J Pers Soc Psychol 89:925-936

Lakens D, Evers ERK (2014) Sailing from the seas of chaos into the corridor of stability: practical recommendations to increase the informational value of studies. Perspect Psychol Sci 9(3):278-292

Lax D, Sebenius J (1986) The manager as negotiator. Free Press, New York

Lee EJ, Nass C (2006) Experimental tests of normative group influence and representation effects in computer-mediated communication. Hum Commun Res 28(3):349-381

Lindskold S, Bentz B, Walters PS (1986) Transforming competitive or cooperative climates. J Confl Resolut 30:99-114

Mallet RK, Huntsinger JR, Sinclair S, Swim JK (2008) Seeing through their eyes: when majority group members take collective action on behalf of an outgroup. Group Process Intergr 11(4):451-470

Maner JK, Luce CL, Neuberg SL, Cialdini RB, Brown S, Sagarin BJ (2002) The effects of perspective taking on motivations for helping: still no evidence for altruism. Pers Soc Psychol B 28(11):1601-1610

Mayer RC, Davis JH, Schoorman FD (1995) An integrative model of organizational trust. Acad Manag Rev 20:709-734

McAllister DJ (1995) Affect- and cognitive-based trust as foundations for interpersonal cooperation in organizations. Acad Manag J 38:24-59

Meyerson D, Weick KE, Kramer HM (1996) Swift trust and temporary groups. In: Kramer RM, Tyler TR (eds) Trust in organizations: frontiers of theory and research. Sage, Thousand Oaks, pp 166-195

Moore CW (1994) Mediator communication and influence in conflict management interventions: a practitioner's reflections on theory and practice. In: Folger JP, Jones TS (eds) New directions in mediation, communication research and perspectives. Sage, Thousand Oaks, pp 209-221

Nadler J (2001) Electronically-mediated dispute resolution and e-commerce. Negot J 17:333-347

Naquin CE, Paulson GD (2003) Online bargaining and interpersonal trust. J Appl Psychol 88:113-120

Neale MA, Bazerman MH (1983) The role of perspective-taking ability in negotiating under different forms of arbitration. Indus Lab Rel Rev 36(3):378-388

Parks CD, Hulbert LG (1995) High and low trusters' responses to fear in a payoff matrix. J Confl Resolut 39(4):718-730

Penn P (1982) Circular questioning. Fam Proc 21:267-280

Prein H (2007) Mediation in praktijk: Beroepsvaardigheden en interventietechnieken, 3rd edn. Boom, Amsterdam

Pruitt DG, Carnevale PJ (1993) Negotiation in social conflict. Brooks/Cole, Pacific Grove

Putnam LL (2004) Transformations and critical moments in negotiations. Negot J 20:275-295

Real T (1990) The therapeutic use of self in constructionist/systemic therapy. Fam Proc 29:255-272 
Ross G (2010) Building trust online: how to adapt mediation and negotiation techniques to the virtual environment. In: Poblet M, Abrahams B, Zeleznikow J (eds) Proceedings of the 6th international workshop on online dispute resolution In conjunction with the $23 \mathrm{rd}$ international conference on legal knowledge and information systems (JURIX 2010), pp 79-85

Ross W, LaCroix J (1996) Multiple meanings of trust in negotiation theory and research: a literature review and integrative model. Intern J Confl Manag 7(4):314-360

Rousseau DM, Sitkin SB, Burt RS, Camerer C (1998) Not so different after all: a cross-discipline view of trust. Acad Manag Rev 23:393-404

Ryan D, Carr A (2001) A study of the differential effects of Tomm's questioning styles on therapeutic alliance. Fam Proc 40:67-77

Savitsky K, Keysar B, Epley N, Carter T, Swanson A (2011) The closeness-communication bias: increased egocentrism among friends versus strangers. J Exp Soc Psychol 47:269-273

Scheel MJ, Conoley CW (1998) Circular questioning and neutrality: an investigation of the process relationship. Contemp Fam Ther 20:221-235

Schoop M, Jertila A, List T (2003) Negoisst: a negotiation support system for electronic business-tobusiness negotiations in e-commerce. Data Knowl Eng 47(3):371-401

Schoop M, Köhne F, Ostertag K (2010) Communication quality in business negotiations. Group Decis Negot 19:193-209

Schoop M, Van Amelsvoort M, Gettinger J, Koerner M, Koeszegi ST, Van der Wijst P (2014) The interplay of communication and decisions in electronic negotiations: communicative decisions or decisive communication? Group Decis Negot 23:167-192

Schweitzer J, Weber G (1997) „Störe meine Kreise!”. Psychotherapeut 42:197-210 .https://doi. org/10.1007/s002780050068

Selvini-Palazzoli M, Boscolo L, Cecchin G, Prata G (1980) Hypothesizing-circularity and neutrality: three guidelines for the conductor of the session. Fam Proc 19:73-85

Sessa VI (1996) Using perspective taking to manage conflict and affect in teams. J Appl Behav Sci 32(1):101-115

Shah A (2004) Using ADR to resolve online disputes. Richmond J Law Technol 10:32-33

Shih M, Wang E, Bucher AT, Stotzer R (2009) Perspective taking: reducing prejudice towards general outgroups and specific individuals. Group Process Intergr Rel 12(5):565-577

Short J, Williams E, Christie B (1976) The social psychology of telecommunications. Wiley, London

Ströbel M, Weinhardt C (2003) The Montreal taxonomy for electronic negotiations. Group Decis Negot 12(2):143-164

Thompson L, Hrebec D (1996) Lose-lose agreements in interdependent decision making. Psychol Bull 120:396-409

Thompson L, Nadler J (2002) Negotiating via information technology: theory and application. J Soc Issues 58:109-124

Thomson R, Murachver T, Green J (2001) Where is the gender in gendered language? Psychol Sci 12:171-175

Todd AR, Galinsky AD (2014) Perspective-taking as a strategy for improving intergroup relations: evidence, mechanisms, and qualifications. Soc Pers Psychol Compass 8(7):374-387

Todd AR, Forstmann M, Burgmer P, Brooks AW, Galinsky AD (2015) Anxious and egocentric: how specific emotions influence perspective taking. J Exp Psychol Gen 144(2):374-391

Tomm K (1984a) One perspective on the Milan systemic approach: part I. Overview of development, theory and practice. J Marital Fam Ther 10:113-125

Tomm K (1984b) One perspective on the Milan systemic approach: part II. Description of session format, interviewing style and interventions. J Marital Fam Ther 10:253-271

Tomm K (1985) Circular interviewing: a multifaceted clinical tool. In: Campbell D, Draper R (eds) Applications of systemic family therapy: the Milan approach, vol 3. Grune and Stratton, New York, pp 34-45

Tomm K (1987a) Interventive interviewing. Part I: strategizing as a fourth guide-line for the therapist. Fam Proc 26:3-13

Tomm K (1987b) Interventive interviewing. Part II: reflexive questioning as a means to enable self healing. Fam Proc 26:167-183

Tomm K (1988) Interventive interviewing. Part III: intending to ask lineal, circular, strategic and reflexive questions. Fam Proc 27:1-15

Van Boven L, Kruger J, Savitsky K, Gilovich T (2000) When social worlds collide: overconfidence in the multiple audience problem. Pers Soc Psychol B 26(5):619-628 
Van der Toorn Y, Van der Wijst P, Damen D (2015) Trust and understanding in face-to-face and online negotiations. In: I Linden, S Liu, F Dargam, J Hernández (eds) Decision support systems IVinformation and knowledge management in decision processes. EWG-DSS 2014, EWG-DSS 2014. Lecture notes in business information processing, vol 221. Springer, Cham

Van Kleef GA, De Dreu KW, Manstead ASR (2004) The interpersonal effects of anger and happiness in negotiations. J Pers Soc Psychol 86(1):57-76

Van Kleef G, De Dreu C, Peitroni D, Manstead A (2006) Power and emotion in negotiation: power moderates the interpersonal effects of anger and happiness on concession making. Eur J Soc Psychol 36:557-581

Vanden Abeele M, Beullens K, Roe K (2013) Measuring mobile phone use: gender, age and real usage level in relation to the accuracy and validity of self-reported mobile phone use. Mob Med Commun $1(2): 213-236$

Veinott ES, Olson J, Olson GM, Fu X (1999) Video helps remote work: speakers who need to negotiate common ground benefit from seeing each other. In: Proceedings of the SIGCHI conference on human factors in computing systems. ACM, pp 302-309

Victorio RM (2001) Internet dispute resolution (iDR): bringing ADR into the 21st century. Pepperdine Disput Resolut Law J 1:279-300

Walther JB, Loh T, Granka L (2005) Let me count the ways the interchange of verbal and nonverbal cues in computer-mediated and face-to-face affinity. J Lang Soc Psychol 24(1):36-65

Walton RE, McKersie RB (1965) A behavioral theory of labor relations. McGraw-Hill, New York

Weigand H, De Moor A, Schoop M, Dignum F (2003) B2B negotiation support: the need for a communication perspective. Group Decis Negot 12:3-29

Wichman H (1970) Effects of isolation and communication on cooperation in a two-person game. J Pers Soc Psychol 16(1):114-120

Wilkinson M (1992) How do we understand empathy systemically? J Fam Ther 14:193-205

Yuan Y (2003) Online negotiation in electronic commerce. Int J Manag Theory Pract 4(1):1-7

Yuan Y, Head M, Du M (2003) The effects of multimedia communication on web-based negotiation. Group Decis Negot 12:89-109

Publisher's Note Springer Nature remains neutral with regard to jurisdictional claims in published maps and institutional affiliations. 